\title{
Ergebnisse hämatologischer Untersuchungen fiir die Aetiologie und Pathologie der Senkung der weiblichen Genitalien.
}

\author{
Von
}

\begin{abstract}
0. Schaeffer, Heidelberg.
(Nach einem auf der Würzburger Versammlung der deutschen Gesellsehaft für Gynäkologie gehaltenen Vortrage.)
\end{abstract}

Hämatologische Studien sind merkwürdigerweise in der Gynäkologie kaum angestellt worden, wenn wir von den Beobachtungen der allgemeinen Blutveränderungen in der Schwangerschaft, bei pelvinen Eiterherden u. dergl. m. hier absehen.

Das für locale hämatologische Studien zunächstliegende Capitel der Gynäkologie wäre dasjenige der "Periodenanomalien". Aber gerade weil es sich hier fast ausschliesslich um Functionen und Functionsstörungen handelt, deren physiologisehe und pathologische Genese durch die Pathologie der Blutbildung und der allgemeinen Blutcirculation stark complicirt wird, zog ich es vor, zuerst die Untersuchungen einer anderen, mit deutlichen anatomischen Veränderungen einhergehenden Krankheitsgruppe, derjenigen der Senkung der einzelnen Genitaltheile, hier vorzuführen. Denn gerade zu dieser ausgesprochenen Lage- und Formveränderung der Organe bildet den Anlass und die Prädisposition wieder eine deutliche Functionsstörung: neben dem gelegentlichen Klaffen der insufficienten Beckenbodenmuskulatur und des zerrissenen Dammes die Störung eines als wenig activ angesehenen Organes, nämlich des elastischen Faser- und Fascienapparates (der Fascia pelvina-visceralis v. Rosthorn's [18]) in dem Lig. cardinale (Kocks) uteri, in dem von vornherein nachgiebigeren Pericystium (Winter, v. Arx) und in dem Subserosium der Excavatio recto-uterina-vagi- 
nalis, secundär erst des auxiliären Haftapparates des Uterus, als welcher sich die glatten Muskelfaserzüge im Grunde der breiten Mutterbänder darstellen.

Ueber den Elasticitätsschwund dieser Gebilde wissen wir so gut wie nichts; erst seit einigen Jahren sind wir einigermaassen orientirt, wo überall in den Sexnalorganen und in welcher Ausdehnung elastische Bindegewebselemente bestehen und wie sich dieselben je nach Alter und Generationsvorgängen in der Gebärmutter verhalten. Im Allgemeinen wissen wir nur, dass das allmähliche, das plötzliche, das wechselnde Nachlassen der Elasticität der unwillkürlich wirkenden contractilen Elemente fast ausnahmslos mit rasomotorischen Störungen gepaart einhergeht. Es ist mir am wahrscheinlichsten, dass letztere den ganzen Vorgang einleiten, d. h. dass die ja einem gemeinsamen nervösen Tonuscentrum unterworfene Gefässmuscularis, bezw. Capillarendothelschicht depressorisch beeinflusst wird und dadurch ein Gewebsödem zu Stande kommt, welches nunmehr secundär die elastischen Bindegewebsfasern zunächst nur beeinträchtigt, auf die Dauer aber ihrer Elasticität beraubt, ja sogar sie der hyalinen Degeneration verfallen lässt, wie wir es bei Multiparis in utero und bei chronischen Metritiden Mehrgebärender sehen.

Nach Landerer (2) nimmt thatsächlich die Elasticität der Gewebe in Folge der andauernden Erhöhung eines auf ihnen lastenden Transsudationsdruckesab. Sowohl bei congestiver wie bei passiver Hyperämie nehmen Gewebsdruck und Gewebsspannung ohnehin zu, da die Wand einer jeden Capillare nur $1 / 3-1 / 2$ des Blutdruckes trägt, den Rest das umliegende Gewebe. Ist der Blutstrom bei gleichzeitiger Hydrämie verlangsamt, so leidet die Elasticität der Gew ebe derart, dass ihr herabgesetzter Gegendruck zum Oedeme führt. Circulationsstörungen und Elasticitätsschwund der den Capillaren anliegenden Gewebe bilden also einen Circulus vitiosus.

Auch bei dem Prolapsus vaginae et nteri sind Circulationsstörungen und Entzündungen bekannt; indessen werden erstere lediglich als Folgeerscheinungen, als Staungen, letztere als Decubitus oder als gelegentliche Bakterieninvasion in das hyperämische oder prolabirte, also Schädigungen mehr ausgesetzte Organ, oder endlich als längst und unabhängig von dem Vorfall bestehende Krankheit angesehen. Dass die Hyperämie eine aus der gleichen Ursache wie der Descensus und dem entsprechend auch von dem frühesten Beginn der Senkung, eventuell schon vorher auftretende Erscheinung sein könnte, welche 
- nach Analogie des oben angeführten Entstehungsmodus des Elasticitätsschwundes -- zu Folge primärer vasomotoriseher Störungen den bindegewebigen Haftapparat der Beckenorgane insufficient werden liesse, ist meines Wissens noch nicht in Betracht gezogen worden.

Und doch können die Schlussfolgerungen, welche aus den im Folgenden wiedergegebenen Mischblutuntersuchungen der Portio vaginalis gezogen werden, kam anders als in diesem Sinne gedeutet werden. Wir hätten es demnach mit einem Loiden zu thun, welches nicht auf die Genitalien beschrïnkt zu sein braucht, wohl aber in den Functionen derselben seine Entstehungsursache oder Veranlassung findet.

Andeutnngen in dieser Richtung sind in dem A. Martin'schen Referat (3) des Würzburger Gynäkologen-Congresses des Jahres 1903 enthalten; der Herr Referent rechnete sogar auf die allgemeine Znstimmung, wenn er diesem Gedanken in dem Sinne Ausdruck verlieh, dass er den Prolaps (abgesehen von den loealen Verletzungen) als Theilersc beinung eines Al lgemeinleidens, von Ermährungsstïrngen anflasste.

Es wurden hiergegen allerdings Stimmen lant [Fritseh (5)]. Da hierbei indessen ins Treffen geführt wurde, dass man doch so häufig gerade bei kräftigen Franen Vorfälle anträfe, so wird hierdurch die oben entwickelte Anschanung nicht beriilıt, vielmehr nur der Begriff "Allgemeinleiden", welcher allerdings zu weitgehend aufgefasst werden kann, aber bei der Kürze jenes Referatsatzes auch nicht gut ander's rrsetzt werden kann. Kräftige Trauen mit Hängebäuchen oder aufgetriebenen Unterleibern giebt es unter den Multiparis Viele. Auf einen derartigen Zusammenhang und analoge Combinationen allein kommt es mir hier abor an. Desgleichen schliessen sich kräftige Gestalten mit Lungenemphysem oder Herzmuskeldegeneration in höheren Alter anch nicht ans.

Kamann (6) endlich stellte aus der Literatur diejenigen Autoren zusammen, die sich in dieser Hinsicht wenigstens geäussert haben [Mangiagalli (7), Secligmann (8) und Coe (9)], dass nimileh der Genitalprolaps in vielen Fällen nur eine Theilersebeinung einer allgemeinen Frnährungsstörung, einer allgemeinen Bindegewebserschlaffung sei in dem Sinne einer Enteroptose oder eines Hängebauches, dass also auf die chirurgische Behandlung noch eine rationelle Allgemeinbehandlung folgen miisse, wozu Martin die entsprechende Prophylaxe auf gleicher Ansich tsbasis hinzufügt. Prophylak tische Maassnahmen im Wochenbette laben Fritsch (10), v. Herff (11), Falk (12), Schrader (13) v. Winckel u. A. schon seither energisch vertreten.

Der vorhergeschickte Gedankengang bewog mich also, in den letzten 3 Jahren bei einer Reihe geeigneter Fälle -- aus über 250 Fällen mit über 1500 Untersuchungen von Senkung und Vorfall wurden als hier geeignet die unten in den Tabellen angeführten Erühstadien ausgewählt - jo eine Probe Mischblut aus der 
Portio vaginalis (mittelst Einstichs entnommen und mittelst Pipette direct in die isotonische Lösung abgesogen) und aus der Fingerbeere (zum Vergleich mit dem allgemeinen Blutbefunde) in einer mittleren isotonischen Jodjodkalilösung (1:2:300 nach Bettmann) auf die Erythrocyten-Resistenz hin zu prüfen.

Das tinctorielle Verhalten ist einer raschen Uebersicht sehr günstig; die Blutkörperehen conserviren sich Wochen und Monate lang gut in dieser Lösung. Für die Beurtheilung wichtig sind 4 Formen, deren Frequenzvechältniss zu einander festgestellt werden muss. lch unterscheide als bedeutsam ausser den einfach dunklen und blassen, noch die granulirten als am wenigsten resistente Zerfallsformen und die jodophilen "hochpotenzirten"Formen, welche sich rubinroth färben, ungemein compact sind und meist die widerstandsfähigste Art repräsentiren. Kommen granulirte oder gar sich völlig entfärbende Formen vor, so ist die Lösung nicht concentrirt genug. Fs liesse sich num leicht der Grad der Isotonie für diese Frythrocyten feststellen durch Anwendung von mehreren Lösungen verschiedener Concentrationen, aber für unsere Zweeke kommt man ebenso weit, wenn die Verhältnisszahl der granulirten zu den übrigen Formen festgestellt wird. Käme es im concreten Falle darauf an, die Resistenz auf das Subtilste festzustellen, so würde ich die international. wohl allgemein anerkannte Hamburger'sche Methode bevorzugen (Prïfung in einer Batterie verschieden concentrirter NaCl-Solutionen). - Die Bezeichnungen "Congestion" und "Stase" in diesem Anfsatze beziehen sich im weiteren Sime auf das jeweilige Ueberwiegen oder Zurïcktreten des arteriellen Affuxes.

Jo venöser das Blut, vor allem je mehr Stase, und je mehr ausgenutzt die Blutkörperehen, desto mehr blasse und granulirte unter den Erythrocyten; je mehr Congestion, desto mehr dunkle; je activer die Congestion bei Vorhandensein besonderer Reizmomento und je geringer die Ausnutzung der Blutkörperchen, 7. B. bei besonders rascher Strömung, worauf ich für die Deutung derartiger Untersuchungen besonders aufmerksam machte, desto intensiver ist nicht nur die Fürbung der dunklen Zellen, sondern auch das Auftreten besonders rubinroth tingirter Erythrocyten, der jodophilen "hochpotenzirten" (so bei Gravidität, beginnender acuter Entzündung, Hyperplasie, Blutkörperchen regencration u. dgl.). Ferner müssen die Gesammtfärbung, die Menge und Farbe des freien körnigen Detritus, die Abschnürungsformen, das Auftreten verklobter Erythrocytenhaufen und die Zahl und Art und Tinction der Leukocyten beachtet werden.

Als geeignete Fälle wurden solche ausgewählt, welche die Frühstadien der Senkung, sei es der Gebärmutter, sei es der Scheidenwandungen (Inversion) repräsentirten. Am beweiskräftigsten erschienen mir diejenigen, welche neben einer deutlich beginnenden oder schon ausgeprägten Oysto- 
184 Schaeffer, Ergebnisse hämatologischer Untersuchungen für die

cele (oder sonstigen Scheideninversion) noch keinen oder nur einen geringen Descensus uteri erkennen, wohl aber schon eine deutliche Aonderung in der Blucirculation der Portio vaginalis, und $z$ war meist eine active, nachweisen liessen.

Nächst dieser Gruppe I "Inversio vaginae" stellte ich die Resultate für die Combination "Retroversio-Flexio + Descensus uteri" als Gruppe II zusammen; ferner III. Einfache Retroversio-Flexio uteri; IV. Einfacher

Gruppe I. Inversio

\begin{tabular}{|c|c|c|c|}
\hline 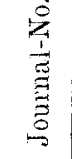 & $\begin{array}{l}\text { Blut- } \\
\text { qualiuat. }\end{array}$ & $\begin{array}{l}\text { Resistenzverhalien der Erythrocyten } \\
\text { (Portiomischblut). }\end{array}$ & $\begin{array}{l}\text { Besonderheiten: } \\
\text { Gentibalien. }\end{array}$ \\
\hline 2826 & I & Wenjg Hochp., mäss. Cong., mäss. Stase. & Retropos. ut. vertic. \\
\hline 784 & $\mathrm{I} \rightarrow \mathrm{II}$ & Starke Hochp., & Retroft. venöse Mens. \\
\hline 268 & II & Stase. & Desc., Antell., sehlaff. \\
\hline 2821 & I & Mäss, Hochp., & Retrov., Dese., Hypopl. \\
\hline 2836 & 1 & - mäss. Stase. & Antefl., Desc, Oligom. \\
\hline 3200 & $\mathrm{I} \rightarrow \rightarrow \mathrm{III}$ & Wenig Hochp., etw. Cong., & Retrofl., Dese., schlaff. \\
\hline 2176 & 1 & Wenig Hochp, Congest. (zieml.stark). & Sehr schlaff, Antofl.,Desc. \\
\hline 2290 & I-- - III & Starke Hochp., & Retrofl., Desc., Ektrop. \\
\hline 2737 & 1 & Starke Hochp., Congest. & Antefi, Desc. Endom. \\
\hline 3128 & {$[I \rightarrow \Pi I$} & Congesti, & Antef., fruil. Dese. \\
\hline 2704 & III & Höherpotenz, & Hypopl., Vertical., Desc. \\
\hline 3113 & $\mathrm{I} \cdots \mathrm{III}$ & Starke Hochp., Congest., ctw. Stase. & Anteff., leicht Desc. \\
\hline 2696 & $\mathrm{II} \rightarrow \mathrm{I}$ & Wenjg Hochp., mäss. Cong., etw. Stase. & Retrofl, Prol. compl. \\
\hline 2848 & III & - mïss. Cong', Stase. & Dese ut. vert. retrop. \\
\hline 3139 & $\mathrm{III} \rightarrow \mathrm{IV}$ & Stase. & Dese. ut rert retrop. \\
\hline 2215 & III $\rightarrow$ II & kaum Cong., & Dosc. ut \\
\hline 2295 & III & Stase. & Retrofl., Desc., steril. \\
\hline 3189 & III & - - - & Desc. ut. rert. retrop. \\
\hline 2317 & III $\rightarrow$ Il & Hochyoten\%, miss. Cong., Stase. & Flong, colli, Dese., Poly p. \\
\hline 2369 & $\mathrm{III} \rightarrow \mathrm{II}$ & - wen. Cong., kam Stase. & \\
\hline 1808 & $I I \rightarrow \infty$ & $\begin{array}{c}\text { - Wen. Gong., hamm stase. } \\
\text { - Congest. }\end{array}$ & $\begin{array}{l}\text { Dese, Retropos. } \\
\text { Desc., Prol. inc. Finor. }\end{array}$ \\
\hline 2814 & $u$ & nüss. Stase. & Desc., Retrov., schlaff. \\
\hline 2157 & III & - rel. kaum Stase. & Desc., Elong., Port.anäm. \\
\hline 3191 & II & Congest. & Desc., Retrofl., cum Pess. \\
\hline 2541 & I & Mäss. Hochpot, Cong. & Retrofl., Desc., 6 W.pp. \\
\hline 2804 & $1 \mathrm{a}$ & Sehr Hochpot., Cong. & Retron., Prol. ing., Elong. \\
\hline 3127 & $\mid \ldots-$ III & Starke Hochp., & Leicht Dese., Motrit. \\
\hline 2991 & $\mathrm{I}$ & Mäss. Hochp., starke Cong. & Retrofl., Desc., Ing.-Hern. \\
\hline 3021 & II & miiss. Stase. & Cystoo., leicht.Desc.,Retr. \\
\hline 3250 & II & Congest, etw. Stase. & Antefl., 1. Desc., Phleb. \\
\hline 2868 & Ia & Zieml.bohePot., s.starkeCong. & Cystocele, leicht. Desc. \\
\hline 3301 & II & Congest. & Desc., Antefl. \\
\hline 3060 & I & Starke Hochp., Congest. & Retrofl., Desc, Metrit. \\
\hline 3091 & I & Zieml. Hochp., Congest. & Desc. ut. vert., Ektrop. il \\
\hline 3109 & II & Congest. & Antefl., Fktrop., Netrit. \\
\hline 2292 & $\mathrm{II} \rightarrow \mathrm{III}$ & Stase. & Retrofl, Dese. \\
\hline
\end{tabular}

Ausserdem vergleiche die mit Subinvolution combiniten Fälle 
Descensus uteri anteflexi sive verticalis — sämmtlich mit und ohne Inversio vaginae; sodann V. Descensus uteri subinvoluti, VI. Gravidität (Abortus, Puerperium) bei Retroflexio (+ Descensus) uteri, VII. Elongatio colli, VIII. Descensus des hypoplastischen (infantilen) Uterus, IX. Prolapsus incompletus et completus uteri, X. Retentio uteri auf operativem Wege oder durch das Pessar, XI. Descensus uteri mit Insufficienz des Pessars oder einer Operation, XII. „Anfgetriebener Leib" nelsen Descensus u. s. w. uteri, XIII. Phlebektasien der Genitalien neben Descensus uteri, XIV. Metritis chronica bei Descensus uteri, XV. Perversitäten bei Descensus uteri.

\section{vaginae (meist Cystocele).}

\begin{tabular}{|c|c|c|c|c|c|c|c|}
\hline \multirow[b]{2}{*}{$\begin{array}{l}\text { Besonderheiten: } \\
\text { im Allgemeinen. }\end{array}$} & \multicolumn{3}{|c|}{ Portio-Erythrocyten: } & \multicolumn{4}{|c|}{ I'inger-Erythrocyten: } \\
\hline & 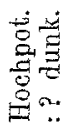 & $\mathrm{d}: 1 \mathrm{bl}$. & $\begin{array}{l}1 \text { gran. } \\
\text { : ? resist. }\end{array}$ & $\begin{array}{l}\text { Blut- } \\
\text { qual. }\end{array}$ & 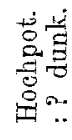 & $\mathrm{d}: 1 \mathrm{bl}$. & $\begin{array}{l}1 \text { gran. } \\
\text { :? resist. }\end{array}$ \\
\hline Herzneurose. & $1 / 17$ & 1.4 & - Leuk. & II $\rightarrow$ III & $(1 / 13)$ & 1,5 & - \\
\hline $42 \mathrm{~J}$ & $1 / 4$ & 1,6 & - & $\mathrm{II} \rightarrow \mathrm{III}$ & $(1 / 7)$ & $1: 1,1$ & - Leuk. \\
\hline$\ldots$ & -14 & 1,2 & 11,0 & III & $(1 / 14)$ & $1: 1,5$ & 1,4 \\
\hline Chlorose, Neurasth. & $1 / 1$ & 1,6 & -- & II & & 4,0 & - \\
\hline Cholelithiasis. & $1 / 15$ & 1,3 & - & II & $(1 / 8)$ & 2,7 & 一 \\
\hline Anäm., Neurasth. & 1,21 & 2,0 & 7,0 & 一 & - & - & - \\
\hline- & $1 / 25$ & 8,7 & - & - & - & - & - \\
\hline Port. im Pess. strang. & $1 / 4$ & 1,8 & 3,0 & II & $(1 / 23)$ & 2,9 & 43,0 Leuk \\
\hline Chlorose. & $1 / 2$ & 4,1 & -1 & $\mathrm{II} \rightarrow \mathrm{III}$ & - & $1: 1.3$ & $\longrightarrow$ \\
\hline Etw. Anäm., Neurasth. & - & 3,4 & 8,0 & - & - & - & 一 \\
\hline Chlorose. & $(1 / 13)$ & $1: 1,8$ & 1,5 & - & - & - & - \\
\hline Steril. Chlorose. & $1 / 4$ & 4,0 & 14,0 & - & 一 & 一 & - \\
\hline Senil, Anämie. & $1 / 20$ & 2,2 & - & II & 一 & 1,1 & - \\
\hline Anämie. & - & 2,3 & 9,0 & $\mathrm{III} \rightarrow \mathrm{IV}$ & 一 & 1,3 & 8,0 \\
\hline Hyst. Spasmen. & - & $1: 1,1$ & 10,0 & - & - & - & - \\
\hline Kräftig. & $\ldots$ & 1,5 & 4,0 & $I I I \rightarrow I$ & $1 / s 0$ & 6.8 & 3,9 \\
\hline Tuss.ut., Saliv., Anäm. & - & $1: 1.2$ & 1,2 & IIl & $(1 / 10)$ & 3,0 & 9,0 \\
\hline Anäm., Neurasth. & - & 1,1 & - & - & - & - & $\ldots$ \\
\hline Kräftjg, Menopause. & $1 / 9$ & 3,2 & 7,5 Lenk. & II & - & 13,0 & 一 \\
\hline Anämie. & - & 1,3 & 11,0 & - & - & - & - \\
\hline Senil. & - & 1,8 & - & $\mathrm{I}[\nrightarrow \mathrm{I}$ & $1 / 20$ & 1,2 & 一 \\
\hline Senil, kräft., Art.-Skl. & - & 4,5 & - & - & -120 & - & - \\
\hline - & 一 & 1,0 & 一 & $11 \rightarrow 111$ & $(1 / 14)$ & $1: 1,4$ & - \\
\hline Senil. & 一 & $1: 1,3$ & - & IV & - & $1: 1,4$ & 4,5 \\
\hline Menopause. & 一 & 3,7 & - & - & - & $一$ & - \\
\hline Anämie. & $1 / 20$ & 4,1 & - & II & - & 1,7 & 14,0 \\
\hline 17 Tage post part. & $1 / 2$ & 2,3 & 一 & 一 & - & - & - \\
\hline Anäm., Hyst. & $1 / 4$ & 1,9 & 29,0 & - & - & - & - \\
\hline Regul. Menorrh., $43 \mathrm{~J}$. & $1 / 10$ & 7,4 & 一 & II & 5,0 & - & - \\
\hline Menopause, 60J.(Ree.) & - & 1,0 & - & - & - & - & - \\
\hline Aufgetr. Leib, Anäm. & 一. & 4,9 & 29,0 & - & - & 一 & - \\
\hline Menop., Ac. Vaginit. & $1 / 6$ & 35,0 & - & - & - & - & - \\
\hline Anämie. & - & 6,0 & - & - & - & - & - \\
\hline Anämie. & $1 / 4$ & 3,2 & - & II & - & 1,5 & - \\
\hline Chlor, Oligomen. & $1 / 5$ & 3,5 & - & III & - & 1,5 & 9,0 \\
\hline Anäm., Neurasth. & - & 4,0 & $\ldots$ & - & - & - & - \\
\hline Chlor., Hyst. & - & $1: 1,5$ & 30,0 & $\mathrm{II} \rightarrow \mathrm{III}$ & $(1 / 17)$ & 2,1 & 12,0 \\
\hline
\end{tabular}

$2519,2958 \mathrm{a}, 2986,2237,3039,2361,3190.3300$ aus Gruppe V. 
Es ergab sich vor allem, dass bestimmte Gruppen uncomplieirter Fäle auch bestimmte Eigenthämlichkeiten in der Blutmisehung der Portio als Abweichung rom sonstigen physiologisehen Mittel (vom Normalen) aufwiesen, so dass wir hier von einer Gesetzmässigkeit reden können, wie es sich aus Folgendem ersehen lïsst. (Siehe Tabolle Gruppe 1.)

Stellen wir die Krgebnisse der Gruppe I zunächst einfach zahlenmässig zusammen: Unter 45 Fällen: 20 nal Hochpotenz, wovon 2 mal höhere Potenz (d. h. nicht rubinrothe Tinetion, sondern ein tTebergang (lazu yon tief dunkelbraun), 28 mal einfache Congestion, 33 mal Stase, u. zw. diese "drei zusammen" 7 mal (bei Hypoplasie, bei bedentender Schlaffheit und post partum, hei Verticalstellung + Herzneurose): 8 mal Hochpotenz + einfache Congestion (wiederholt bei Hetrit. chron. cum Antefl. + Desc, bei Retrofl. + Desc. einer $43 \mathrm{j}$, bei incompl. Prolapsus einer Greisin, bei incompl. Prol. + Elong. + Puerper., und wieder 6 Wochen post partum mit Retrofl. + Desc.); 5 mal allein einfache Congestion (boi hochgradiger Erschlaffung oder kiktropion + Vescensus und Anteflexio, bei Descensus einer Greisin): 11 mal alleir Stase (wiederholt bei Metrit. chron. + Subinv. + Dese, bei Dese. einer Xl p., bei einf. Dese, bei Retrofl. + Desc. einer anüm. Sterilen, bei Phlobelst + Retrof. + Dese. und 2 mal bei l)ese. und Elong. colli einer Senilen. -- Dio übrigen 15 Fälle sind Paarungen ron Stase mit je einer Art Congestion, woron $6 \mathrm{mal}$ mit Hochpotenz (bei Hypoplasie mehrmals oder bei Ektropion), $9 \mathrm{mal}$ mit Congestion (meist Retropos. ut. desc. oder complicirter Anteft. ut. -... Metrit., Phlebelt. - und einf. Retrofi. ut.

Das häufige Auftreten hochpotenzirter (stark jodophiler) und congestiver Rrythrocyten bei Inversio vaginae ist unverkennbar und tritt um so deutlicher hervor, wenn andere bestimmte Gruppen hiermit vorglichen werden, und zwar "Retroflexio + Descensus nteri" und noch mehr "Subinvolntio uteri", bei denen die Maximal-Frequenzziffern sich von der Hochpotenz und Congestion zur Stase hin verschieben.

Hingegen treffen wir bei den Gruppen "Retroflexio" und "Anteversio + Descensus" analoge congestive, ja noch höher gesteigerte Blutmischungsverhältnisse, wic bei der Inversio vaginae. Folgende Tabelle giebt eine Uebersicht derart, dass in jeder Gruppe die Resultate, welche durch Fälle von "Subinvolution " beeinflusst sind, in Klammern beigefügt sind.

Es giebt hier also:

1. eine Gruppe mit ansgesprochener Hochpotenzirung und Congestion $(+\leftarrow)$ : Retroflexio uteri sine descensu.

Die Falle von beginnendem, leichtem Descensus uteri aller Gruppen gehören mit an alogem Resultate hierhin, nämlich mit $55 \mathrm{pCt}$. Hochpotenz, $66 \mathrm{pCt}$. Congestion und nur $33 \mathrm{pCt}$. ausgesprochener Stase. 
Aetiologie und Pathologie der Senkung der weiblichen Genitalien. 187

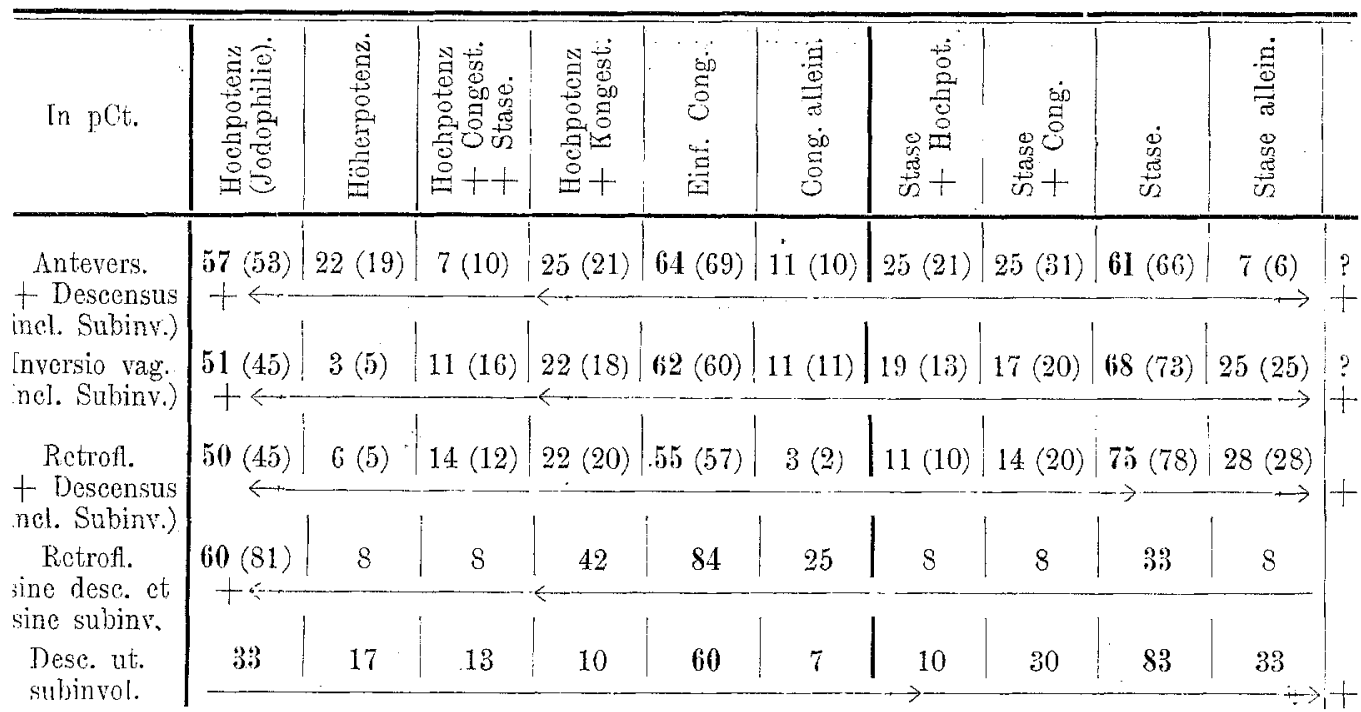

2. zwei Gruppen mit vorwiegender Stase $(\rightarrow+)$ : als Lebergangsstadium Descensus uteri retroflexi und noch mehr Descensus uteri subinvoluti,

3. zwei Gruppen mit stark divergirenden Extremen, Hochpotenz und Stase, wobei aber das Uebergewicht auf Seite der Congestion liegt $(+\longleftrightarrow \longleftrightarrow)$ : Inversio vaginae, Descensus uteri anteversi.

Jjic Uebersicht der Durchschnittsindices der BIutqualitäten verdeutlichen dieses Resultat nach den Gruppen wie folgt: Leicht. Dese. $1, \overline{5}$, Retrofl. allein 1, 7 , Inversio rag. 1,85, Dese. ut. anteversi 1,9-2,0, Desc. ut. retrofl. 2,1, Dese. ut. subinvol. 2,3.

Da die "Inversionsfälle", wenn sie auch in der Ueberzahl zur Congestion und Hochpotenz hinneigen (Auftreten stark jodophiler Erytbrocyten), doch sehr mit Fälien venöser Stase gemischt sind, und da vor allem in den einzelnen Fällen neben der Congestion eine bedeutende venöse Anschoppung besteht, so ist es a priori wahrscheinlich, dass hier Begleitmomente vorbanden sind, welche nach der einen oder anderen Seite aussehlaggebend sind.

In der That gelangen wir an der Hand obiger casuistischer Notizen zu folgenden Sätzen:

1. In der Combination von Inversio vaginae + Retroflexio oder Hypoplasia des fast immer etwas tiefer getretenen Uterus oder + Elongatio colli oder Metritis (Erosio) oder Prolapsus incompletus uteri oder Puerperium liegen Reizmomente für das reichliche Auftreten hochpotenzirter Erythrocyten im Mischblute.

2. Hingegen finden wir bei Inversio + Metritis oder oft nur leichtem, beginnendem Descensus meist uteri anteflexi oder 
retropositi oder Descensus eines senilen Uterus eine einfache Congestion, welche um so häufiger mit Stase gepaart ist, je ausgeprägter der Descensus ist, und dann eine danernd gewordene Erschlaffung der Arterienwandungen $=$ arteriellen Afflux ohne höhere Potenzirung der Erythrocyten und ohne Strombeschleunigung repräsentirt.

3. Die Inversio + Subinvolutio uteri oder Desc. à. retrofl. einer schwächlichen Sterilen oder + Phlebektasien oder anderen Complicationen neben Desc. ut. retrofl. oder Desc. ut. senilis geht gepaart mit venöser Stase, die aber selten hochgradig ist, woraus hervorgeht, dass

die Inversion an sich keine Stase hervorruft oder mit einer solchen gepaart geht, es sei denn, dass die Gebärmutter sich gleichfalls crheblicher zu senken begonnen hat, und selbst dann compensirt die Inversio vaginae die Stase bis zu einem abschwächenden Grade durch reichliche Beimischung höher potenzirter arterieller Elemente, sofern es sich um ein lebhaft actives Organ handelt. Das ätiologische Moment der Cystocele ist also ein Congestion erregendes; denn die Cystocele an sich kann umgekehrt doch nicht als ein solches angesehen werden, zumal es hier sich uicht um eine einfache vorübergehende Congestion handelt, sondern um eine dauernde, die zudem noch durch die Strombeschleunigung oder durch Beimengung stark jodophiler, hochpotenzirter Blutelemente des Charakters einer Erschlaffungshyperämie entkleidet ist.

In aufälliger Weise wird dieser Process der Beimischung höher potenzirter Erythrocyten beeinflusst durch die sub 1 aufgeführten Combinationen, vor allem die Retroflexio uteri. Wir hatten diese Wahrscheinlichkeit schon aus unserer Vergleichstabelle S. 187 und zwar aus der "Retroflexionsgruppe" entnommen. Die Bestätigung ist um so frappanter, als damit der ätiologische Causalnexus $z$ wischen Descensus-Inversio und Retroversio-flexio (Küstner, Martin, v. Winckel) auch von dieser Seiteher wieder dargethan wird, und zwar besteht hier offenbar nicht nur ein rein mechanischer Zusammenhang, vielmehr ein innerer genetisch gemeinsamer und für beide Erscheinungen zugleich wirkender!

Auch die schon von den älteren Operateuren gewürdigte Bedeutung der Inversion der vorderen Scheidenwand und des in ihr liegenden Blasendivertikels für das Weiterschreiten des Ge- 
sammtprolapses kommt in diesen Untersuchungen zum Ausdruck, aber es tritt hier mehr das gemeinsame ätiologische Moment für Scheide, Blase und Gebärmutter in den Vordergrund, weil hier Frühstadien zur Untersuchung gelangten: Bei den Anfangsstadien der einfachen Senkung der Scheide und Gebärmutter finden wir die einfache Congestion vorherrschend. Jüngst noch erklärten Pfannenstiel und Schauta die Cystocele für eine Hauptgefahr des Vorfalles der Gebärmutter.

Die Retroflexio uteri treffen wir 1 mal oder ofter auf je 2 Falle von hochpotenzirter oder umgekehrt vorwiegend venöser Blutmischung hingegen nur auf 4 Fälle von einfacher Congestion. Die Retroflexionsfälle mit mangelhafter Blutversorgung umfassen fast ausschliesslich mehr oder weniger inactive Organe (Hypoplasie, Menopause) oder mangelhaft involvirte. Die Retrofexionsfälle mit höhcrpotenzirter Erythrocytenzufuhr sind vorwiegend puerperaler oder metritischer Natur, während die wenigen congestivon Fälle die Retroflexion nichi gesenkter Lteri betreffen.

Die Retroflexio uteri also compensirt ersichtlich die in allen Fällen von Combination des erheblicheren Descensus uteri mit Inversio vaginae vorhandene venöse Stase, sofern sich diesc Organe noch in lebhafter Function oder Reaction befinden; ist nämlich ein so beschaffener Uterus retroflectirt, so treffen wir nicht nur neben der venösen Stase eine höhere Potenzirung der Blutkörperchen, wobei die Stase meist nicht bedeutend ist, sondern auch in nicht so seltenen Fällen neben einer reinen Congestion, die allerdings zuweilen wie beim gleichzeitigen completen oder incompleten Prolaps durch eine Dauererweiterung auch der Arterien erklärbar wird. Finden wir trotz der Retroflexio in einzelnen Fällen nur eine venöse Stase, so wird dieselbe, nach den Beispielen dieser Gruppe durch, weitere Anschoppung hervorrufende, Begleitmomente verständlich (z. B. Subinvolution, Phlebektasien u. a.).

Immerhin kommen wir auch hier wieder zu der Erkenntniss des alten Satzes: Die Retroversio-flexio uteri ist keine physiologische Lage und Haltung des Organes; sie geht also, wie wir aus dem Bisherigen entnehmen können, mit erheblichen und auf die Dauer weiterc Erscheinungen hervorrufenden Blutcirculationsstörungen gepaart und zwar von Frühstadien an. Die einfache Retroversioflexio uteri rangirt in dieser Hinsicht gleich der einfachen Inversio vaginae mit beginnender Senkung der Gebärmutter, sogar anscheinend noch energischer congestiv beeinflusst. - Beide als Anfangsstadien analoger Vorgänge!

Pfannenstiel drückt sich sehr klar aus: Die "Retroversion 
des Uterus repräsentirt diejenige Stellung, welche er für die dermalige Beschaffenheit des Bandapparates am zweckmässigsten haben kann." Dieser kann o ongenital abnorm sein: asymmetrisch zu kurz oder zu straff und unelastisch. Aber diese Fälle betrachten wir an anderer Stelle, sie gehören zur Hypoplasie. Der Bandapparat kann erworbenerweise gelockert oder in seiner Elasticität beschädigt sein: durch Entzündungen oder durch Subinvolution, d. h. durch Hyperämie, wie der Uterus selbst und seine Nachbarorgane ebenfalls. Wir sehen nun aus unseren Blutuntersuchungen, dass es sich hierbei keineswegs, wie a priori anzunehmen, um eine venöse Stase oder, wie bei den Subinvolutionsfällen, allein um eine einfache dauernde Erweiterung der Arterien durch Erschlaftung handelt, sondern um eine im Beginn recht active, hochpotenzirte Hyperämie!

Wir bemerken auch weitere Beeinflussungen sowohl der Eirnährung und des Wachsthums der betreffenden flectirten Wand, als auch der zugehörigen Portiohälfte: Beide sind hyper-

Gruppe II. Descensus

\begin{tabular}{|c|c|c|c|}
\hline $\begin{array}{l}\frac{1}{3} \\
\frac{1}{5} \\
\frac{3}{3} \\
\frac{3}{3}\end{array}$ & $\begin{array}{l}\text { Blut- } \\
\text { qualität. }\end{array}$ & $\begin{array}{l}\text { Resistenzverhalten der Erythrogten } \\
\text { (Portio-Misehblut). }\end{array}$ & $\begin{array}{l}\text { Besonderhoiten } \\
\text { an den Genitalien: }\end{array}$ \\
\hline $\begin{array}{l}2919 \\
2893 \\
2475 \\
2846 \\
1880 \\
3101 \\
2260 \\
2187 \\
2801 \\
2491 \\
2100 \\
2547 \\
2255 \\
3200 \\
22942 \\
22929 \\
3137 \\
2808 \\
3097 \\
3033 \\
3129\end{array}$ & 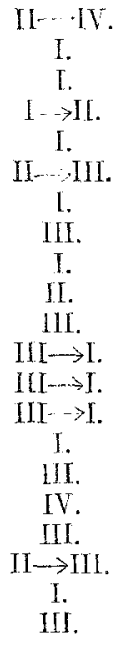 & 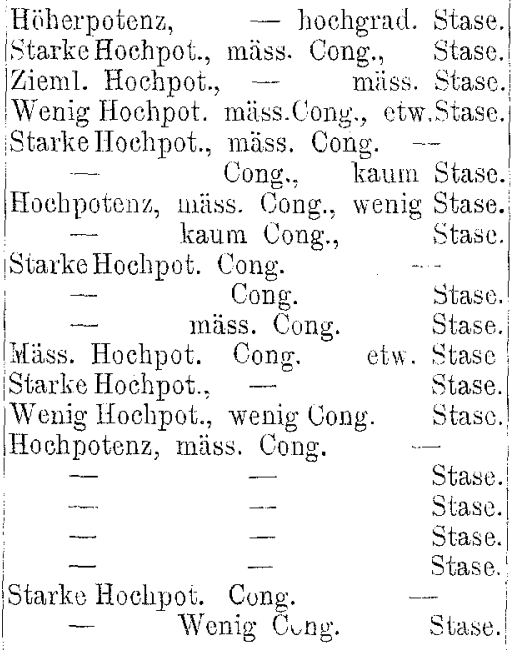 & $\begin{array}{l}\text { Menses zu oft. } \\
\text { Cum pess. } \\
\text { Leicht.Desc., Irreg. Mens. } \\
\text { Retrov., cum pess. } \\
\text { Leicht. Desc., cum pess. } \\
\text { Leicht. Dese., Myome. } \\
\text { Oft Menorrhagien. } \\
\text { Gute lage post Kolporrh. } \\
\text { Leicht. Desc., Lros. } \\
\text { Retroy, Subinvolut. } \\
\text { Desc. ovar. } \\
\text { Retrov, steril. } \\
\text { Pelveoperit. chron. } \\
\text { Invers., Phlebeet., Lazor. } \\
\text { Retrov.-Vertic-Stellung. } \\
\text { Dysmen. irreg. } \\
\text { Suppr. mens. } \\
\text { Leicht. Dese., Retrop. } \\
\text { Kolporrh., cum pess. } \\
\text { Desc. ut. retrov. } \\
\text { Dese. ut. retrop. Klimax. }\end{array}$ \\
\hline
\end{tabular}

Ausserdem vergl. die Fälle 2290, 2292, 2294, 2295, 2369, 2541, $2814,2868,2991,3021,3060,3200,3191,3139,3189$ ats Gruppe 1, 
plastisch und die entsprechende Muttermundslippe erodirt. Auch rufen retinirte Eitheile die gleichen Erscheinungen an den entsprechenden Organhälften durch Circulationsbeeinflussung hervor.

Sind alle diese aus den Beobachtungen gezogenen Schlüsse und Voraussetzungen richtig, so werden wir sie bei den Betrachtungen der anderen Gruppen bestätigt oder jeweilig eingeschränkt finden. Die Combination "Retroflexio und Descensus uteri (mit und ohne Inversio vaginae)" gewährt uns einen Einblick in die Blutversorgung der Gebärmutter unter dem Einfluss dieser drei Factoren und gleichzeitiger Hauptbetonung der Ketroversio-flexio. Ueber die Deutung der betreffenden Formen der Hyperämie soll zum Schlusse abgehandelt werden.

Die zahlenmässigen Ergebnisse der Gruppe II sind:

Unter 36 (49 mit Einschluss der Subinvolutionsfälle) Fällen 18 (22) mal Hochpotenz, 20 (28) mal einfache Congestion, 27 (38) mal Stase, und zwar diese "drei zusammen" 5 (6) mal (bei Sterilen, bei Menorrhagien oder zu häufigen Menses Anämischer, bei Phlebektasien); 8 (10) mal Hochpotenz (meist mässig) + einfache Congestion

uteri retroversi-flexi.

\begin{tabular}{|c|c|c|c|c|c|c|c|}
\hline \multirow[b]{2}{*}{$\begin{array}{l}\text { Besonderheiten } \\
\text { im Allgemeinen: }\end{array}$} & \multicolumn{3}{|c|}{ Portio-Erythrocyten: } & \multicolumn{4}{|c|}{ Finger-Erythroeften: } \\
\hline & 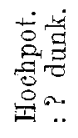 & $d: 1$ bl. & $\begin{array}{l}1 \text { gran. } \\
\text { :? resist. }\end{array}$ & 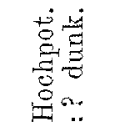 & $\mathrm{d}: 1 \mathrm{bl}$. & 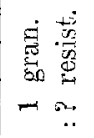 & $\begin{array}{l}\text { Blut- } \\
\text { qual. }\end{array}$ \\
\hline Hyst., Uratharn. & $(1 / 10)$ & $1: 1,5$ & 2,2 & II. & $(1 / 23)$ & 1,3 & - \\
\hline Hyst. u. Anäm: & $1 / 3$ & 1,3 & - & 11. & - & $1: 2,0$ & Leuk. \\
\hline Klimax. & $1 / 6$ & 1,1 & - & II. & $(1 / 7)$ & 1,1 & - \\
\hline Menorrh, Hypopl. & $1 / 53$ & 2,8 & - & II $\rightarrow$ III. & $(1 / 11)$ & 2,1 & 28,0 \\
\hline Chlor., Neurasth. & $1 / 3$ & 1,8 & - & II. & $(1 / 20)$ & $1: 1,1$ & - \\
\hline Chlor., Neurasth. & - & 3,0 & 53,0 & II. & $(1 / 20)$ & $1: 1,1$ & - \\
\hline Anämic. & $1 / 11$ & 2,5 & - & UI. & - & 4,2 & - \\
\hline Vagina straff. Hyst. & - & $1,3-1$ & $21,1--9,0$ & $\mathrm{II} \rightarrow \mathrm{III}$. & $(1 / 17)$ & 1,2 & 12,0 \\
\hline Amenorrh., Hyst. & $1 / 4$ & 8,1 & - & II. & - & 4,8 & 一 \\
\hline Anämie. & - & 5,3 & 23,0 & II_-III. & $(1 / 30)$ & 4,7 & 8,0 \\
\hline Chlor., Neurasth. & - & 3,7 & 26,0 & - & - & - & - \\
\hline Irreg. Oligomen. & $1 / 11$ & 4,4 & 7,0 & III. & $1 / 8$ & 1,0 & 2,3 \\
\hline 1.2000 & $1 / 3$ & 2,0 & 11,0 & II $\rightarrow$ IIl. & - & 1,0 & 23,0 \\
\hline Anïrn., Abort. & $1 / 18$ & 1,3 & 11,0 & - & - & - & 二 \\
\hline Chlorose. & $1 / 4.7$ & 3.9 & $\ldots$ & II. & - & 3,3 & 25,0 \\
\hline Neurasth. & - & $1: 1,1$ & 17,0 & $\mathrm{II} \leftrightarrow \mathrm{MII}$. & $(1 / 17)$ & 2,1 & 12,0 \\
\hline Chlor., Neurasth. & - & $1: 1,3$ & 2,1 & - & - & - & - \\
\hline FI.alb., Hyst. (Spasm.) & - & $1: 1.3$ & 11,0 & 一 & - & $\ldots$ & - \\
\hline Anäm., Suppr. mens. & $\therefore$ & $1: 1,2$ & - & 一 & - & - & - \\
\hline Etw. anämisch. & $1 / 4$ & 4,9 & - & - & - & - & - \\
\hline Venter propend. & - & 1,7 & 17,0 & - & - & - & - \\
\hline
\end{tabular}

und bei gleichzeitiger Suhinvolution 1884, 2848, 2976, 3305, 3146, 2747, $3051,2491,2958 \mathrm{a}, 2986,2237,3009,3300$ aus Gruppe V. 
(3 mal bei Inversio, bei Amenorrhoe post part, bei Metritis chron., wiederholt bei Retroversio oder leichtem Descensus); 4 (5) mal Hochpotenz + (meist mässiger) Stase (in der Klimax), 1 mal stärkere Stase, wo Collum durch Pessar hindurchgetreten and eingeschnürt, bei Pelveoperitonit chron. gon, stets mit Erosionen); 1 mal einfache Congestion (bei Subinvolution und Menorrbagie einer Anämischen); 5 (10) mal Congestion + Stase (bei Amenorrhoe und Klimax, post Colporrh., bei leich tem Desc. + Myomatose, bei Desc. or.); 10 (14) mal Stase allein (bei Degener, = Sterilität und irreg. Menses, bei Phlebekt. und Inversion, bei hochgradiger Subinvolution und bei Operirten $=$ erfolgreicher Fixur und Colporrh.).

Nicht häufiger als bei der Inversion finden wir hicr das Auftreten hochpotenzirter, stark jodophiler Zellen; aber auffallend ist das iiberwiegend häufige gleichzeitige Auftreten von wenig resistenten Erytbrocyten, überhaupt das häufige Vorkommen veñöser Stase, sodass wir an den beiden Exiremen Maxima zu verzeichnen haben und die letzterc bei gleichzeitigem Zurückbleiben der Congestion den Ausschlag giebt, wie die Pfeilrichtung in der Tabelle S. 187 andeutet.

Woher die Gegensätze? Wir finden

nebeneinander Hochpotenz (fast ausnahmslos) und Stase (fast immer) bei Retroversio-flexio + Descensus (nicht immer mit gleichzeitiger und dann stets mässiger, einfacher Congestion), also vorwiegend active Hypcrämic neben Erschlaffung; die Stase fehlt nur, wenn die Gebärmutter sich nicht in ausgesprochener Retroflexion befindet, also in verticaler Haltung, zumal wenn gleichzeitig Scheideninversion besteht, -- oder unter dem EinHuss des Puerperium bei herannahendem Periodentermine. Eine nur geringe Stase treffen wir gepaart mit nur leichtem Descensus und mit Inversio vaginae.

Also: 1. Retroversio-flexio + Descensus uteri geht gepaart mit hochpotenzirter Congestion und Stase;

2. Je geringer der Descensus, je ausgeprägter die alleinige Retroversio-flexio oder deren Cumbination mit Inversio vaginae, desto geringer die Stase, bis zum völligen Fehlen derselben, d. h. Eintreten der Congestion!

3. Subinvolutio uteri, Genitalphlebektasion, Sterilität, Climakterium, Descensus ovariorum gehen gepaart mit Erschlaffung der Gefässwandungen, sowohl arterieller wie venöser, ohne Herbeiführung hochpotenzirter Erythrocyten, und veranlassen besunders häufig Menorrhagien oder zu häufige Menses (also Fälle einfacher Congestion oder Stase, event. Beide neben einander). 
4. Treten die in 3. genannten Factoren und Erscheinungen zu den in 1. genannten Retrofl. und Desc. hinzu, so finden wir auch die Stase bedeutender und die einfache Congestion der in 1. angeführten Formel hinzugefügt.

In diesem Befunde liegt die Bestätigung, dass die Frühstadien des Senkungsprocesses eingeleitet werden durch eine sehr active Congestionshyperämie, - dass umgekehrt der fortgeschrittene Tiefertritt und die hochgradige Scheidenwand-Erschlaffung sich combiniren mit zunehmender Gefässerschlaffung, und zwar sowohl der Arterien wie der Venen (einfache Congestion und Stase), wobei der Zugang hochpotenzirter Elemente in Folge verschiedener Begleitmomente fortbestehen kann; auf Letztere kommen wir später zurück.

Die zahlenmässigen Ergebnisse der Gruppe III sind:

Unter 13 (20 incl. Subinvolutionsfällen) Fällen 8 (12) mal Hochpotenz, wovon $1 \mathrm{mal}$ höhere Potenz, $11 \mathrm{mal}$ einfache Congestion, 4 mal Stase, und zwar diese „drei zusammen" 1 mal; 6 mal Hochpotenz + einfache Congestion, 1 mal Hochpotenz + Stase, 3 mal einfache Congestion, 1 mal Congestion + Stase, 1 mal Stase allein.

11 Fälle reiner Retroversio-flexio uteri ohne Spur einer Senkung der Gebärmutter (vergl. Gruppe III) ergaben das fast ausschliessliche Vorkommen arterieller Congestion, und zwar sogar überwiegend der activen höher- und hochpotenzirten Form. Die hinzutretende, z. Th. nur mässige venöse Anschoppung treffen wir bei der Combination mit Inversio vaginae, das Vorkommen einer erheblicheren Stase bei gleichzeitiger Subinvolutio post partum oder Hypoplasie der Genitalien.

Unter dem Einflusse der „Auftreibung des Abdomens" finden wir nur einfache Congestion; möglicherweise deutet dieses darauf hin, dass bei jener "Auftreibung " im Wesentlichen Arterien im Spiel: sind, so dass eine eigentliche venöse Stase nicht zu Stande kommt.

Bei Tabelle IV tritt wieder die Beimischnng hochpotenzirter Erythroeyten zur Compensation der venösen Stase zu Tage; am meisten kommt die einfache Congestion zur Geltung. Wie aus den casuistischen Angaben zu ersehen, ist die Blutmischung. hier stark von Begleitmomenten abhängig, und zwar ist (siehe Tabelle IV)

1. bei dem reinen Descensus am häufigsten die Stase in Combination mit jedem Grade der Congestion, kaum allein; am häufigsten mit der einfachen Congestion combinirt, und zwar: 
194 Sohaelfer, Ligebnisse hämatologischer Untersuchungen für die

Gruppe III. Einfache

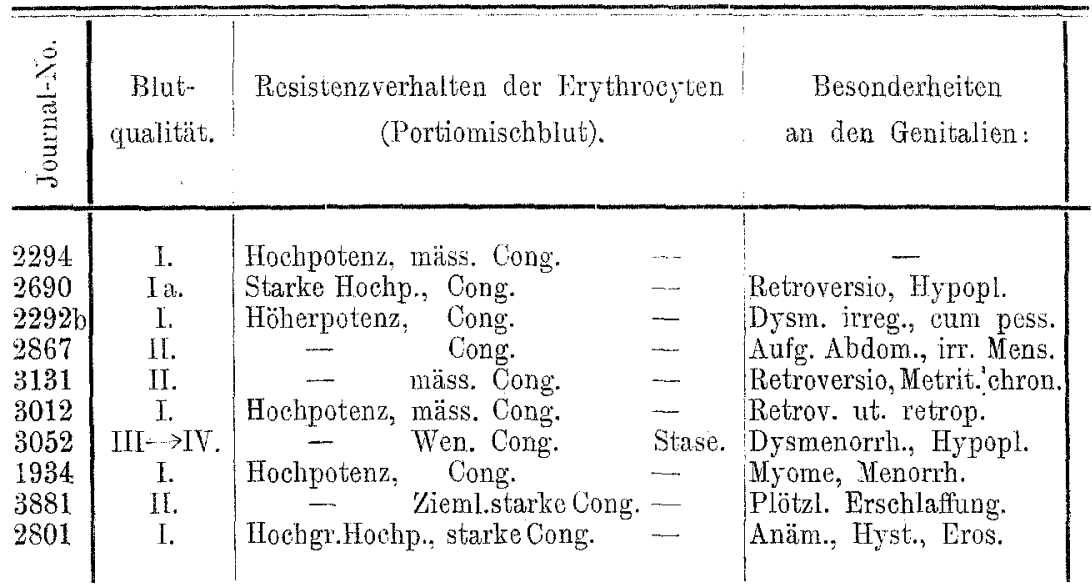

Ausserdem vergl. die mit Inversio vaginae combinirten Fäle 2292, 2784,2826 aus Gruppe I und bei gleichzeitigen Subinvolution 2387,

Gruppe IV. Einfacher Descensus

\begin{tabular}{|c|c|c|c|c|c|}
\hline 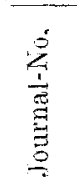 & $\begin{array}{l}\text { Blui- } \\
\text { qualitat. }\end{array}$ & \multicolumn{3}{|c|}{$\begin{array}{l}\text { Resistenzverhalten der Erythrocyten } \\
\text { (Portiomisehblut). }\end{array}$} & $\begin{array}{l}\text { Besonderheiten } \\
\text { an den Genitalien: }\end{array}$ \\
\hline 1604 & [. & Hochpotenz, & Congestion & - & $\begin{array}{l}\text { Spastische Erschoinung. } \\
\text { Steril. }\end{array}$ \\
\hline 2453 & III. & Etw. Höherpot.: & wonig Cong. & Plase. & Subinvol., Desc. oval. \\
\hline 2855 & III $>1$. & Höherpotenz, & - & Stase. & $\begin{array}{l}\text { Leicht. Dese, aufgetr. } \\
\text { Leib. }\end{array}$ \\
\hline 1735 & TV. & $\ldots$ & Cong., & Stast. & Perversit., Kreuzweh. \\
\hline 3120 & II $\rightarrow$ ill. & $\ldots$ & wenig Cony. & Stase. & Hypopl. ut. \\
\hline 2386 & $I I I \rightarrow I$. & Mäss. höhterc l'o & t., - $\quad$ mä & ss. Stase. & Desc. ov. sin. \\
\hline 2491 & III - ]. & Hochpotenz. & - & ss, Stase. & Metrit. Fros..ven. Menorrb. \\
\hline $3091 \mathrm{a}$ & [IIT- I. & Etw. Hochpot., & - & Stasc. & Ektr., Cystoc., Menorrh. \\
\hline 3100 & I. & Etw. Höherpot., & Cong., & -.. & Elong. colli, Menorrh. \\
\hline 2514 & III. & Höherpotenz, & $m \ddot{a}$ & ss. Stase. & Desc. ov sin. \\
\hline 3083 & I. & Hochpotenz, & mäss. Cong., & - & Netrit., Eros. \\
\hline 1704 & III $\rightarrow$ II. & - & Mäss. Cong., we & iig Stase. & Perversitäten. \\
\hline 3090 & II. & - & Cong., & - & Pelveoperit. adh. \\
\hline $2268 \mathrm{a}$ & 1. & erpot & Congest. & - & Invers. Vag. Metrit chron. \\
\hline 200 & III. & $x^{2}$ & $\ldots$ & Stase. & Dese. nt. retropos. vertic. \\
\hline
\end{tabular}

Hierzu vergl. die mit Inversio vaginae combinirten Fälle 2737 , $2268,3091,3128,3250,3301,3127,3115,2215,1808,2836,2645$, 2868 aus Gruppe I und bei gleichzeitiger Subinvolution 1839, 2361, 3190,3039 aus Gruppe V.

Die zahlenmässigen Ergebnisse der Gruppe IV sind nämlich: Unter 28 Fällen (32 incl. Subinvolutionsfällen) 16 (17) mal Hochpotenz, wovon 6 mal Höherpotenz, 18 (22) mal Congestion, 17 (21) mal Stase. Alle 3 zusammen 2(3) mal (stets Subinvolution), 7 mal Hochpotenz + 
Retroversio-flexio uteri.

\begin{tabular}{|c|c|c|c|c|c|c|c|}
\hline \multirow[b]{2}{*}{$\begin{array}{l}\text { Besonderheiten } \\
\text { im Allgemeinen: }\end{array}$} & \multicolumn{3}{|c|}{ Portio-Erythrocyten: } & \multicolumn{4}{|c|}{ Finger-Erythrocyten: } \\
\hline & 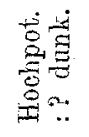 & $d: 1 b l$. & $\begin{array}{l}1 \text { gran. } \\
: \text { ? resist. }\end{array}$ & $\begin{array}{l}\text { Blut- } \\
\text { qual. }\end{array}$ & 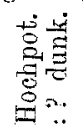 & $\mathrm{d}: 1 \mathrm{bl}$. & 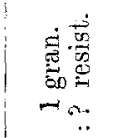 \\
\hline Anäm.. Chlorose. & $1 / 16$ & 5,0 & - & II. & - & 3,3 & 25 Leuk. \\
\hline Chlor., Oligom. & $1 / 2$ & 7,1 & Jueuk. & II. & - & 8,0 & 28,0 \\
\hline Anäm., Hyst. & $(1 / 5)$ & 3,9 & 一 & III $\rightarrow$ II. & $(1 / 17)$ & 2,1 & 12,0 \\
\hline Irreg. Mens., Steril. & - & 5,6 & - & III. & - & $1: 1,7$ & 8,0 \\
\hline Chlor., Neurasth. & - & 3,0 & - & li. & - & 3,2 & - \\
\hline Endometr. gon., Eros. & $1 / 6$ & 3,7 & - & II. & $(1 / 30)$ & 1,2 & 28 Leuk. \\
\hline Anämie. & - & 1,5 & 5,6 & IIII. & - & $1: 1,1$ & 5,0 \\
\hline Anämie. & $1 / 10$ & 4,4 & - & - & - & - & 一 \\
\hline Anäm.,Neur. Suppr.M. & - & 5,4 & - & - & - & 一 & 一 \\
\hline Hyst.. Suppr. mens. & $1 / 4$ & 8,1 & - & II. & 4,3 & - & - \\
\hline
\end{tabular}

uteri anteversi sive verticalis.

\begin{tabular}{|c|c|c|c|c|c|c|c|}
\hline \multirow[b]{2}{*}{$\begin{array}{l}\text { Besonderheiten } \\
\text { in Allgeneinen: }\end{array}$} & \multicolumn{3}{|c|}{ Portio-Erythrocyten: } & \multicolumn{4}{|c|}{ Finger-Erythrocyten: } \\
\hline & 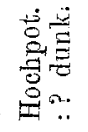 & $\mathrm{d}: 1 \mathrm{bl}$. & $\begin{array}{l}1 \text { gran. } \\
\text { :? resist. }\end{array}$ & $\begin{array}{l}\text { Blut- } \\
\text { qual. }\end{array}$ & 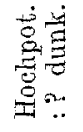 & bl. & 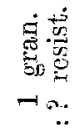 \\
\hline Kräftig. & $1 / 5$ & 2,3 & 一 & II. & $(1 / 50)$ & $1: 1,5$ & 38,0 \\
\hline Oligomen & $(1 / 25)$ & 1,5 & 3,0 & III. & — & 6.0 & 30.0 \\
\hline Rel. Anäm. & $1 / 20$ & $1: 1,4$ & 8,0 & III. & $(1 / 8)$ & $: 1,1$ & $\begin{array}{l}11,0 \\
\text { Leuk. }\end{array}$ \\
\hline Hyst., Chlorose. & - & 7,6 & 7,8 & - & -- & $-\frac{1}{a-a}$ & - \\
\hline Geringe An & Jeuk. & 1,5 & 37,0 & II. & - & 6,0 & - \\
\hline Dyspeps. n & $1 / 14$ & 3,0 & 7,0 Leuk. & III $\rightarrow$ I. & $1 / 13$ & 3,1 & 7,0 \\
\hline or., Neur., Pervers. & $1 / 6$ & 4,9 & 14,0 & $\mathrm{III} \rightarrow \mathrm{II}$. & $1 / 35$ & 4,6 & 8,1 \\
\hline Oligom. & $1 / 24$ & 1 & 20 & III. & - & 1 & 9,0 \\
\hline & $(1 / 15)$ & 6,4 & - & II. & - & 2,8 & - \\
\hline 41 & $1 / 11$ & 1,7 & 3,5 & III, & - & 1,4 & 6,0 \\
\hline , Menorrh. & $1 / 7$ & 2,4 & - & - & - & - & $\therefore$ \\
\hline Chloasm. & - & 5,3 & 23,0 & III. & - & $\mathbf{3}$ & -. \\
\hline & - & 5 & - & II. & - & 2,3 & - \\
\hline & $1 / 11$ & 3,3 & - & III. & $(1 / 14)$ & $1: 1,5$ & 1,4 \\
\hline Spasmen. & - & $1: 1,3$ & 11,0 & - & - & 一 & - \\
\hline
\end{tabular}

Congestion ( 4 mal Cystocele, 1 mal Elong. colli, 2 mal bei Perversen, auch Metritis), 7 mal Hochpotenz + Stase (3 mal Cystocele, 2 mal Desc. ov. turg., Metritis (Eros., Ektrop.), leichter Desc. ut. bei aufgetriebenem Leibe), 7 (10) mal Congestion + Stase (6 mal Cystocele, 3 mal Subinvolution, ferner wiederholt Perversitäten, 1 mal Hypoplasia), 3 mal Congestion allein ( 2 mal Cystocele, 1 mal Pelveoperitonit. adh.), 3 mal Stase allein (1 mal Cystocele, 1 mal Desc. ut. retropos. vest.). 
zusammen mit höherer Potenz, oder mit einer jeden allein, derart dass

entweder die Venen erweitert sind und durch Reizmomente oder primäre Vorgänge höher potenzirte Erythrocyten beigemengt sind (z. B. bei Subinvolution + Unterleibs- oder Genitalentzündungen, Spasmen, Hypoplasie, Dese. ov. - Anfangsstadium des Descensus), oder alle Arterien dauernd erweitert sind und auch hier nur unter dem Einflusse bestimmter Reiz- oder weiterer Erschlaffungszustände höher potenzirte Zellen oder Venenblut beigemischt sind (z. B. bei Inversio vag. und unter dem Einflusse von Metritis, Perversitäten).

2. Bei der Inversio vaginae + einfachem Descensus uteri treffen wir fast ausschliesslich die einfache Congestion an (nicht vorwiegend Hochpotenz wie bei Inversio + Retrofl. Desc.), höchstens gepaart mit venöser Blutanschoppung. Bei dieser Combination tritt also die arterielle oder (bezw. und) venöse Erschlaffung in den Vordergrund.

3. Bei der Subinvolutio uteri + Dese tritt constant die Stase zur Congestion hinzu.

Das ganze hämatologische Verhalten des Descensus uteri anteversi ohne und noch mehr mit Inversio vaginae dentet auf eine dauernde arterielle und seltener venöse Erschlaffung, weniger auf eine active Hyperämie hin, wie sie bei dem Descensus uteri retroflexi deutlicher ist. Die Frühstadien auch des Dese. ut. anteversi lassen die Beimischung hochpotenzierter Erythrocyten, also noch active Hyperämic erkennen. Der Desc. at. anteversi repräsentirt, wenn er mit der Inversio vaginae vergesellt ist, kein Frühstadium mehr, im Gegentheil ein bis zur Erschlaffungserweiterung sowohl arterieller wie venöser Gefässe vor geschrittenes Stadium. Hiermit beginnen die makroskopisch längst bekannten, zum Oedem der Portio führenden Circulationsstörungen. Bei bedeutenderen Vorfällen ist schwer zu entscheiden, wann die lediglich durch mechanische Behinderung entstehende Stauung und Gefässerweiterung beginnt und sich der von mir hier supponirten primären activen Hyperämie aufpfropft.

Ist die arterielle und die venöse Gefässerweiterung eine gleichmässig gesteigerte, so ist bei der Zählung schwer zu entscheiden, $o b$ es sich hier um eine Hyperämie handelt oder nicht. $\mathrm{Tu}$ bedenken ist, dass bei einer noch weiteren Steigerung oines 
der beiden Factoren über dieses Maass der Gleichmässigkeit hinaus scheinbar nur eine Art der Hyperämie festgestellt wird; es müssen also stets die anatomischen und functionellen Befunde mit in Betracht gezogen werden. Gewöhnlich fallen aber doch erhebliche Differenzen nach Zahl und Tinction, zumal gegenüber der nie zu unterlassenden Fingerbeerblutsprobe, auf.

Die Sonderstellung der Gruppe $V$ der nach einer Entbindung oder Fehlgeburt mangelhaft rü ekgebildeten Genitalien erschien schon a priori zweckmässig, ergab sich aber auch aus den Betrachtungen der Complicationen in den übrigen Gruppen als nothwendig. Die einschlägigen im Seitherigen gemachten Nebenbefunde werden hier bestätigt.

Ziffernmässig stellen sich die Befunde Gruppe $\mathbf{V}$ wie folgt:

Unter 32 Fällen 10 mal Hochpotenz, wovon 3 mal mässige und 5 mal Höherpotenz, 20 mal einfache Congestion, 24 mal Stase, und zwar 4 mal diese "drei zusammen" (Retrof 1 . + Cystocele oder puerp.); 3 mal Hochpotenz + einfache Congestion (bei Retrofl.); 3 mal Hochpotenz + Stase (1 mal Antefl. mit Dese. ut. et ov., sonst Retroversio); 4 mal einfache Congestion allein (Erschlaffung mit Desc. ov. oder Ektropion); 9 mal einfache Congestion + Stase (stets geringfügig bei Antefl. + Desc. mit blasser Menorrh. und bei Retrov.-pos. ut., i. Allg. bei Antefl. oder Retrov.-fl. + Cystocele oder cum pess.); 10 mal Stase (bei Retrofl. II.-III. Grad. oder mit anderen ausgeprägten Erschlaffungserscheinungen: Cystocele, Eros., cum pess., Pelveoperitonit. adh.).

Das Zurücktreten der Hochpotenz und der activen Congestion und das Hervortreten der Stase und daneben der einfachen, vielfachen Erschlaffungs-Congestion sind zu betonen, derart dass sich folgender Satz formuliren lässt:

Bei der Subinvolutio uteri kommt ohne einen besonderen anderen Grund (z. B. Retrofl. ut.) kein Zufluss hochpotenzirter Erythrocyten, vielmehr ausschliesslich eine dauernde passive Erschlaffungsausdehnung der Arterien und Venen vor (einfache Congestion und Stase), aber oft so verhältnissmässig gleichmässig, dass trotz der ersichtlichen Blutüberfüllung des Organes die Mischung nicht erheblich von der mittleren physiologischen differirt; - daher finden wir bei der Blutuntersuchung meist mässige Congestion, mässige Stase.

In zwei Fällen der jüngsten Zeit (2881, 3402) - abgesehen von zahlreichen Fehlgeburtsfällen - beobachtete ich im Anschluss an Suppressio mensium eine acute Erschlaffungsretroflexio uteri und bei Beiden trat innerhalb weniger Tage ein Verschwinden der hochpotenzirten Congestion mit Strombeschleunigung ein und an deren Stelle eine einfache ziemlich starke Erschlaffungscongestion, d. h. die dunkel gefärbten Erythrocyten blieben in der gleichen starken Ueberzahl, ver- 
Gruppe V. Descensus

\begin{tabular}{|c|c|c|c|}
\hline$\frac{\dot{0}}{\frac{i}{3}}$ & $\begin{array}{l}\text { Blat- } \\
\text { quali- } \\
\text { tät. }\end{array}$ & $\begin{array}{l}\text { Resistenzyerhalten der Erythrocyten } \\
\text { (Portiomischblut). }\end{array}$ & $\begin{array}{l}\text { Besonderheiten: } \\
\text { an den Genitalien. }\end{array}$ \\
\hline 2881 & II & Congest. & Retrofl.II. nach Suppr.m. \\
\hline 3305 & II & Stase. & Retrov.-fl., schlaff. \\
\hline 3300 & II & etw. Stase. & Retrofl., Cystoc. \\
\hline 3190 & $\mathrm{I} \rightarrow \mathrm{II}$ & Mass. Hochpot., Cong., & Oystoc., Men., Antefl. \\
\hline 3039 & II & - mäss. Cong., Stase. & Antefl., Oystoc., Ektrop. \\
\hline 2361 & III & mäss. Cong., & Antefl., Cystoc, or. Nab. \\
\hline $2958 \mathrm{a}$ & IV & Stase. & Retrov, Cystoc. \\
\hline 1884 & $I[\rightarrow]$ & Höherpotenz, mäss. Cong. & Retrofl., Dese. \\
\hline 2237 & II & mäss. Stase. & Retrofl, Cystoc., Menorrh. \\
\hline 1839 & II & mäss. Cong., mäss. Stase. & Antefl., blasse Menorr. \\
\hline 2387 & III & Stase. & Retrofl. II-IIT \\
\hline 2436 & II & Congest. & Retrov., Fktrop. \\
\hline 2486 & III & Stase. & Retrofl. \\
\hline 2721 & I & StarkeHochpot., wenig Cong., & Retrofl., $71 / 2$ W. post part. \\
\hline 2519 & II & Etw. Höherp., starke Cong, etw. Stase. & Retrofl., Invers., irr. II. \\
\hline 2847 & I & Höherpotenz, & Retrov. \\
\hline 2976 & $I \rightarrow I I$ & Etw. Höherp., mäss. Cong. & Retroff, Desc, Menorrh. \\
\hline 3064 & I & Mäss.Hochpot., Congest. & Retrofl. \\
\hline 3070 & II $\rightarrow$ III & Stase. & Retrofl., Eros. spl. \\
\hline 2453 & III & Höherpotenz; & Antefl, Dese. ovar. \\
\hline 3146 & II & Congest., (etw. Stase). & Retrof. \\
\hline 2744 & $\mathrm{III} \rightarrow \mathrm{IV}$ & Stase. & Retrofl., Perit. adh. \\
\hline 3051 & II & mäss. Cong., etw. Stase. & Retrov.-pos. \\
\hline 2491 & $1 \mathrm{II} \rightarrow \mathrm{I}$ & Congest., & Retrof. \\
\hline $\begin{array}{l}2958 \\
3303\end{array}$ & $\mathrm{II}->\mathrm{III}$ & 二 & Retrov.; cum pess. \\
\hline $\begin{array}{l}3300 \\
3009\end{array}$ & $\underset{\mathrm{II}}{\mathrm{III}} \mathrm{IV}$ & mäss. Cong., etw. Stase. & Retroll. \\
\hline $\begin{array}{l}3009 \\
2848\end{array}$ & II & Mäss. Hochpot., - leichte Stase. & $\begin{array}{l}\text { Retrov., Cystoc., Menorm. } \\
\text { Retrov., Wenig Desc. }\end{array}$ \\
\hline $\begin{array}{l}2848 \\
3009_{a}\end{array}$ & II & mäss. Cong., ctw. Stase. & $\begin{array}{l}\text { Reurov., Wenig wesc. } \\
\text { Antefl., cum pess. }\end{array}$ \\
\hline $3009 \mathrm{~b}$ & II & hochgrad.Cong., - & Retrofl. II". Desc. ovar. \\
\hline 2986 & $\mathrm{III} \rightarrow \mathrm{IV}$ & wenig Congest, & Retrofl., Cystoc. \\
\hline 3402 & II & Congestion. & Retrofi. III0, Cystoc. \\
\hline
\end{tabular}

loren aber erheblich an Jodtinktion, während die hochpotenzirten Jodophilen völlig verschwanden; eine Stase trat aber noch nicht ein!

Die Ursache ist kemeswegs in den zu den Genitalien ab- und zuführenden Gefässen zu suchen, nicht einmal ausschliesslich in den Gefässwandungen des Uterus selbst, sonderı vor Allem in dem Gewebe der Gebärmutterwand, welches nach mehr oder weniger grossem Verluste seiner Elasticität die Gefässwandungen nicht genügend durch Gewebsgegendruck unterstützt, zumal nicht die Capillarendothelien. Die arteriellen Capillaren erweitern sich dadurch, ohne dass die zuführenden Arterien, zumal nicht die Stammarterien, sich entsprechend mit ausdehnen. Die zuströmende Blụtmenge für die unverhältnissmässig vergrösserte Aufnahme- 
uteri subinvoluti.

\begin{tabular}{|c|c|c|c|c|c|c|c|}
\hline \multirow[b]{2}{*}{$\begin{array}{l}\text { Besonderheiten: } \\
\text { im Allgemeinen. }\end{array}$} & \multicolumn{3}{|c|}{ Portio-Erythrocyten: } & \multicolumn{4}{|c|}{ Finger-Erythrocyten: } \\
\hline & 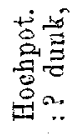 & d: 1 bl. & $\begin{array}{l}1 \mathrm{~g} \\
: ? \text { resist. }\end{array}$ & $\begin{array}{l}\text { Blut- } \\
\text { qual. }\end{array}$ & 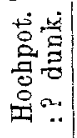 & $\mathrm{d}: 1 \mathrm{bl}$. & $\begin{array}{l}1 \mathrm{~g} \\
: \text { ? resist. }\end{array}$ \\
\hline Anäm., Neurasth. & - & 5,4 & - & - & - & - & - \\
\hline Chlor., Menorrh. & - & $1: 1,9$ & 6,0 & - & - & $\ldots$ & - \\
\hline Chlorose. & 一 & 3,1 & 23.0 & - & 一 & - & - \\
\hline Anämie. & $1 / 12$ & 3,2 & 27,0 & -- & - & - & - \\
\hline Anäm., Basedow. & - & 2,6 & 44,0 & II & - & 2,4 & 20,0 \\
\hline Anäm., XI. p. & - & 3,0 & 34,0 & - & - & - & - \\
\hline Anäm., kräft., hyst. & - & $1: 3,0$ & 7,0 & - & - & - & 一 \\
\hline Kräftig. & $(1 / 4)$ & 1,4 & 一 & $一$ & - & - & - \\
\hline Chlorose, Dysmen. & - & 2,3 & - & $\mathrm{II}$ & 一 & 6,7 & - \\
\hline- & - & 4,0 & - & - & - & - & - \\
\hline Mager, Anäm. & - & $1: 2,0$ & 15,0 & - & - & - & - \\
\hline Anăm., Neurasth. & - & 7,4 & - & III & $1 / 8$ & 2,7 & 6,2 \\
\hline Anämie. & - & $1: 1,9$ & 4,0 & $\mathrm{II} \rightarrow \mathrm{III}$ & - & 2,5 & 7,0 \\
\hline Anäm., stillt nielit mehr. & $1 / 5$ & 1,4 & - & III & $(1 / 11)$ & $1: 1,5$ & 15,0 \\
\hline Chlorose. & $(1 / 40)$ & 10,0 & - & IT & $1 / 15$ & 16,0 & - \\
\hline Anämie. & $1 / 5$ & 1,4 & - & III & $(1 / 11)$ & $1: 1,5$ & 15,0 \\
\hline Anämie. & $(1 / 10)$ & 3,3 & 一 & II & - & 3,0 & - \\
\hline Chlorose, Menorrh. & $1 / 12$ & 5,9 & - & III $\rightarrow$ IV & - & 1,6 & $4,6^{2}$ \\
\hline Chlorose, Neurasth. & - & 1,0 & 46,0 & II & - & 1,4 & - \\
\hline Anärn., 4 W.p.p.imm. & $1 / 30$ & 1,5 & 3,0 & III & 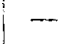 & 6,0 & 30,0 Leuk \\
\hline Chlor., Amenorrh. & - & $4,3-2,0$ & - & - & - & - & - \\
\hline Anämie. & - & 1,1 & 5,0 Leuk. & $\mathrm{II} \rightarrow \mathrm{III}$ & - & 2,5 & 7.0 \\
\hline Chlor., Menorrh. & - & 2,0 & 50,0 & 一 & - & - & - . \\
\hline Chlor., Neurasth. & $1 / 6$ & 4,9 & 14,0 & II $\rightarrow \rightarrow$ III & $1 / 30$ & 4,7 & 8,0 \\
\hline Kräft., Anämie. & - & 1,2 & - & - & - & - & - \\
\hline Chlorose. & - & $1: 1,2$ & 6,0 & - & - & - & $\rightarrow$ \\
\hline Anämie. & $\overline{1}$ & 2,7 & - & IV & - & $1: 1,1$ & 3,0 \\
\hline $\begin{array}{l}\text { Skrofulös. } \\
\text { Anämie. }\end{array}$ & $\underline{1 / 13}$ & $\begin{array}{l}1,4 \\
2,0\end{array}$ & - & 11 & - & 1,4 & - \\
\hline $\begin{array}{l}\text { Anämie. } \\
\text { Etw. Anämic. }\end{array}$ & - & $\begin{array}{r}2,0 \\
28.0\end{array}$ & - & - & $\ldots$ & - & - \\
\hline $\begin{array}{l}\text { Etw. Anämie. } \\
\text { Anämie. }\end{array}$ & - & 2,0 & 10,0 & $\sim$ & $\ldots$ & - & - \\
\hline Hochgr.Hyst.,Supp.M. & - & 5.4 & $\ldots$ & $\ldots$ & - & - & - \\
\hline
\end{tabular}

capacität des davor liegenden Capillarnetzes bleibt also nahezu die Gleiche wie früher, es sei denn, dass der arterielle Blutdruck ein grösserer würde. Auf die Daner würde jedenfalls, wenn die abführenden Venen-Capillaren und -Aeste sich nicht erheblich verengen würden, was sie in der That nicht thun, in dem Capillarensystem ein Vacuum entstehen, welches dadureh verhindert wird, dass der Blutstrom in den Verienplexus verlangsamt wird, sich also in die arteriellen Capillaren zurückstaut. Gewebsserum zurückzusaugen sind die. Capillaren auch nicht mehr in nennenswerthem Maassstabe fähig, weil das Bindegewebe eben unter einem zu gegeringen Eigendruck steht. Ein Zurück- oder Weiterpressen des 
Gruppen VI-XII. Verschiedene hämatologisch

\begin{tabular}{|c|c|c|c|}
\hline 总 & $\begin{array}{c}\text { Blut- } \\
\text { qualität. }\end{array}$ & $\begin{array}{l}\text { Resistenzverhalten der Erythrocten } \\
\text { (Portiomischblut). }\end{array}$ & $\begin{array}{l}\text { Besondorheiten } \\
\text { an den Genitalien: }\end{array}$ \\
\hline 2492 & 1. & Hochpotenz, einf. Cong., etwas stase. & $\begin{array}{l}\text { Collum gleitet durchs } \\
\text { Pessar. }\end{array}$ \\
\hline 2290 & $\mathrm{I} \rightarrow \mathrm{II} \rightarrow \mathrm{III}$ & Hochpotenz, - Stase. & $\begin{array}{l}\text { Collum gleitet durehs } \\
\text { Pessar. }\end{array}$ \\
\hline 2696 & $\mathrm{II} \rightarrow \mathrm{I}$ & Höherpotenz, mäss. Cong,, - & $\begin{array}{l}\text { Jahrelang Prol. compl. } \\
\text { Invers. sine pess. }\end{array}$ \\
\hline 1808 & $\mathrm{II} \rightarrow \mathrm{J}$ & - einf. Cong.: & Invers. Ineompl. Prol. \\
\hline 3097 & II $\leftrightarrow I I I$. & Stase. & Post Kolp., Suppr. M. \\
\hline 2304 & Ia. & Sehr hochpot, einf. Cong, & 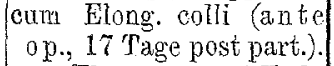 \\
\hline 2401 & $I I \rightarrow 1$ & Rü̈ckg. d.Hochp., einf. Cong., noch Stase. & $\begin{array}{l}\text { cum Elong. e. post Kol- } \\
\text { porrhaph. (7 Woch. }) \\
\text { in normal. Antevers. }\end{array}$ \\
\hline 2187 & 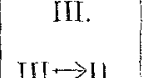 & - & Vag. straffer durch Ante- \\
\hline 2541 & III $\rightarrow \mathrm{II}$ & $\begin{array}{r}\text { Weniger Hochpot, weniger einf. Cong., } \\
\text { weniger Stase, }\end{array}$ & $\begin{array}{l}\text { Durch Repos. ein. Retro- } \\
\text { flexio ut.g-rav.partial. }\end{array}$ \\
\hline 2961 & II. & $\begin{array}{r}\text { Wegfall d. Hochpot., mohr Cong., etwas } \\
\text { Stase. }\end{array}$ & $\begin{array}{l}\text { Durch Pessar Antefl, } \\
\text { porher Retrof. cum dese. } \\
\text { Infantiler Oterus. }\end{array}$ \\
\hline 3009 & 11. & Auftret. höher. Pot., - & $\begin{array}{l}\text { D ureh Pessar, Cür. } \\
\text { u. Aetzung. Antefl., vor- } \\
\text { her Retrofl. cum desc., } \\
\text { T.p. ex Subinyol. }\end{array}$ \\
\hline 2846 & {$[--11$.} & - einf. Cong., - & $\begin{array}{l}\text { Menorrh., Fl. alb. } \\
\text { Retrof. cum dese } \\
\text { ut. infant. }\end{array}$ \\
\hline 2919 & I. & Hochpotenz, mäss. Cong., etwas Stase. & $\mid \begin{array}{c}\text { Zu oft Menses, Retrofi. } \\
+ \text { Dese. }\end{array}$ \\
\hline $\begin{array}{l}2893 \\
2814\end{array}$ & $\begin{array}{l}\text { I. } \\
\text { I. }\end{array}$ & $\begin{array}{l}\text { Hochpoten/, mäss. Cong., } \\
\text { Hochpot., mäss. einf. Cong., ctwas Stase. }\end{array}$ & \begin{tabular}{l|l}
3 & Retroh. + Dese. \\
Invers., Retroll.
\end{tabular} \\
\hline 2290 & $1 \rightarrow I I--I I I$. & Hochpotenz, - Stase. & Retroft., Invers.,Fros. \\
\hline 2292 & I. & Höherpot., mäss. einf. Cong., - & $\because$ Retrof., Dysm. irreg. \\
\hline $\begin{array}{l}2991 \text { I } \\
\text { Vgl. G }\end{array}$ & II, 2991. & Mäss. Hochpot., Cong., & $\begin{array}{l}\text { Retrolt., Dese., regul. } \\
\text { Menorth. }\end{array}$ \\
\hline 2958 & $I I \rightarrow \rightarrow I I$ & - etwas Stase. & $\mid \begin{array}{c}\text { Retrofl.. Desc, Sub- } \\
\text { inv., Habit., Aborte. }\end{array}$ \\
\hline
\end{tabular}

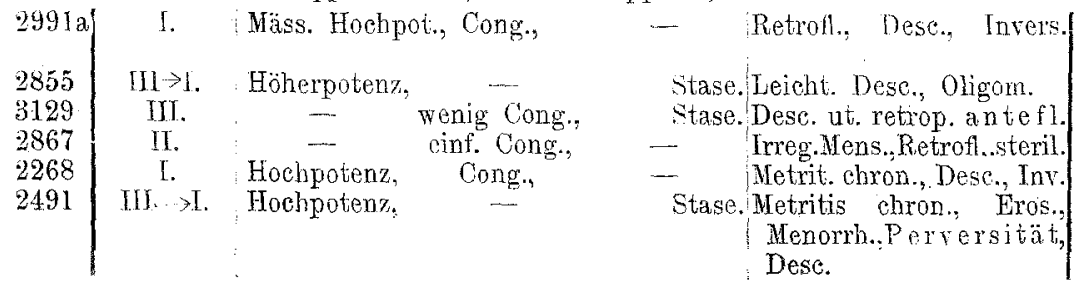


Aetiologie und Pathologie der Senkung der weiblichen Genitalien. 201

\section{complicirende Momente bei dem Descensus uteri.}

\begin{tabular}{|c|c|c|c|c|c|c|c|}
\hline \multirow[b]{2}{*}{$\begin{array}{l}\text { Besonderheiten } \\
\text { in Allgemeinen: }\end{array}$} & \multicolumn{3}{|c|}{ Portio-Erythrocyten: } & \multicolumn{4}{|c|}{ Finger-Erythrocyten: } \\
\hline & 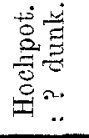 & $\mathrm{d}: 1 \mathrm{bl}$ & $\begin{array}{l}1 \text { gran. } \\
\text { : ? resist. }\end{array}$ & $\begin{array}{l}\text { Blut- } \\
\text { qualität. }\end{array}$ & 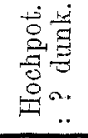 & $d: 1 \mathrm{bl}$ & 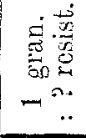 \\
\hline Desc. ov. Ulcer. port. & $1 / 6$ & 5,0 & - & $\mathrm{II} \rightarrow \mathrm{IIII}$ & - & 5,3 & 19,0 \\
\hline Eros., Ektropion. & $1 / 4$ & 1,8 & 3,0 & II. & $(1 / 23)$ & 2,9 & 43,0 \\
\hline Senil, Chlor. & $1 / 20$ & 2,2 & $一$ & II. & - & 1,1 & - \\
\hline Senil, kräft, Art.-Sk1. & - & 4,5 & - & - & - & - & - \\
\hline An. Dese. Retrofl. II ${ }^{0}$. & $\overline{1 / 2}$ & $\begin{array}{c}1: 1,2 \\
2,3\end{array}$ & - & $\mathrm{I}_{\rightarrow} \rightarrow \mathrm{II}$ & - & 4,3 & Teuk. \\
\hline- & $(1 / 15)$ & 6,1 & 12,0 & $\mathrm{I} \rightarrow \mathrm{II}$ & - & 4,3 & Leuk. \\
\hline Kräftig. & - & 1,0 & 2,1 & III & $(1 / 25)$ & 1,2 & 12,0 \\
\hline- & $1 / 18$ & 7,4 & 13,0 & III. & $1 / 92$ & 2,2 & 20,0 \\
\hline - & $\cdots$ & 4,0 & 9,0 & III $\ldots$ II. & - & 4,0 & 10,0 \\
\hline - & $(1 / 12)$ & 2.8 & - Leuk. & IV. & - & $1: 1,1$ & 3.0 \\
\hline - & $1 / 53$ & 2,8 & 一 & III $\rightarrow$ II. & $(1 / 11)$ & 2,1 & 28,0 \\
\hline Hyst., Uratharn. & $1 / 3$ & 1,3 & - & II. & $(1 / 23)$ & 1,3 & - \\
\hline Hyst, Anäm. & $1 / 3$ & 1,3 & 一 & II. & - & $1: 2,0$ & Leuk. \\
\hline $\begin{array}{l}\text { Kräfti., Hyst., Colit. } \\
\text { muc. }\end{array}$ & $1 / 15$ & 1,7 & 一 & III $\rightarrow I I$. & $\left({ }^{1} \tilde{\mathfrak{l}}_{14}\right)$ & $1: 1,4$ & - \\
\hline $\begin{array}{l}\text { Pessar schnürt. } \\
\text { Hyst, Anäm. }\end{array}$ & $1 / 4$ & 1,8 & 3,0 & II. & $\begin{array}{l}(1 / 23) \\
\text { Leuk. }\end{array}$ & 2,9 & 43,0 \\
\hline Anäm., Hyst. & $(1 / 5)$ & 3,9 & - & $I I I \rightarrow I I$ & $(1 / 17)$ & 2,1 & 12,0 \\
\hline $\begin{array}{l}43 \mathrm{~J} . \text { Sehr schlaffe } \\
\text { Vagina. }\end{array}$ & $1 / 10$ & 7,4 & - & II. & - & 5,0 & - \\
\hline Hydrops pedis. & - & 1,2 & 一 & - & - & -1 & - \\
\hline $\begin{array}{r}\text { Andere Fälle Re } \\
\text { Gruppe }\end{array}$ & $\begin{array}{l}\text { tentio } \\
\text { IV, } 2\end{array}$ & $\begin{array}{l}\text { ut. du } \\
491 ; G r\end{array}$ & $\begin{array}{l}\text { reh pess } \\
\text { uppe } Y\end{array}$ & $\begin{array}{l}\text { r: Gruppe } \\
53,3009\end{array}$ & $\begin{array}{l}\text { II, } 218 \\
3305 .\end{array}$ & 7,1880 & \\
\hline $\begin{array}{l}\text { Hern. A ufgetrieb. } \\
\text { Leib. }\end{array}$ & $1 / 1 \mathrm{~B}$ & 7,4 & - & III.$-\rightarrow$ II. & $(1 / 17)$ & 2,1 & 12,0 \\
\hline Anfgetrieb. Leib. & $1 / 38$ & $1: 1,4$ & 8,0 & III. & $(1 / 8)$ & $1: 1,1$ & 11,0 \\
\hline $\begin{array}{l}\text { Aufgetr.Leib, Klim. } \\
\text { Aufgetrieb. Jeib. }\end{array}$ & - & $\begin{array}{l}1,7 \\
5,6\end{array}$ & $\underline{17,0}$ & $\overline{\text { III. }}$ & - & $\overline{1: 1.7}$ & $\overline{8.0}$ \\
\hline Kräftig. & $1 / 11$ & 3,3 & $\overline{10}$ & III. & $(1 / 14)$ & $1: 1,5$ & 1,4 \\
\hline$\cdots$ & $1 / 6$ & 4,9 & 14,0 & III. & $1 / 30$ & 4,7 & 8,0 \\
\hline
\end{tabular}


202 Schaeffer, Trgobnisse hämatologischer Unterswohungen für die

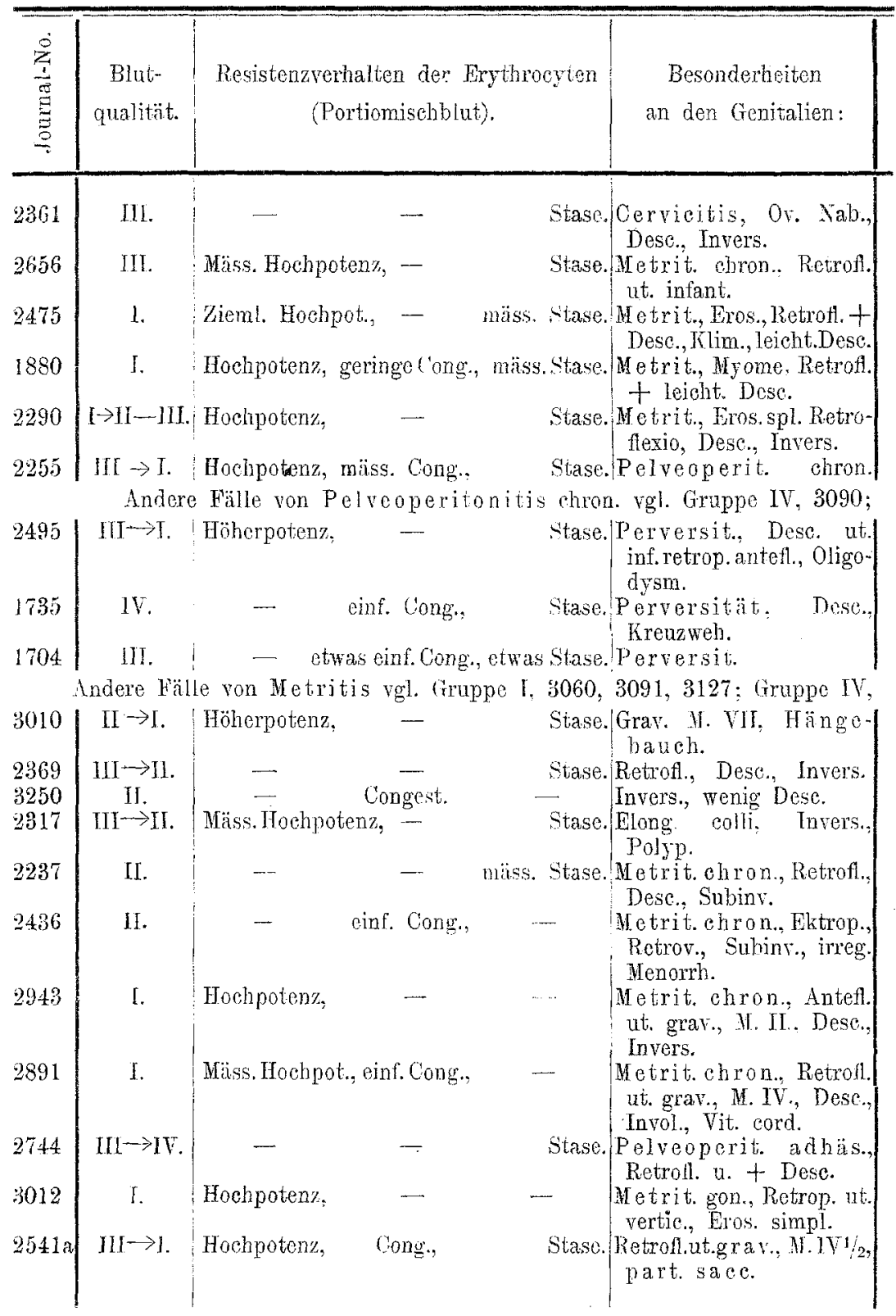

übersehüssigen Blutserums (Lymphe) wird von dem Gewcbsdruck demnach auch nur in unvollkommenem Grade geleistet.

Der Elasticitätsschwund der Gewebe der Uteruswand ist also die der allgemeinen Gefässerweiterung innerhalb der Wandung vorausgehende Anomalie; sie selbst entsteht im Puerperium und 


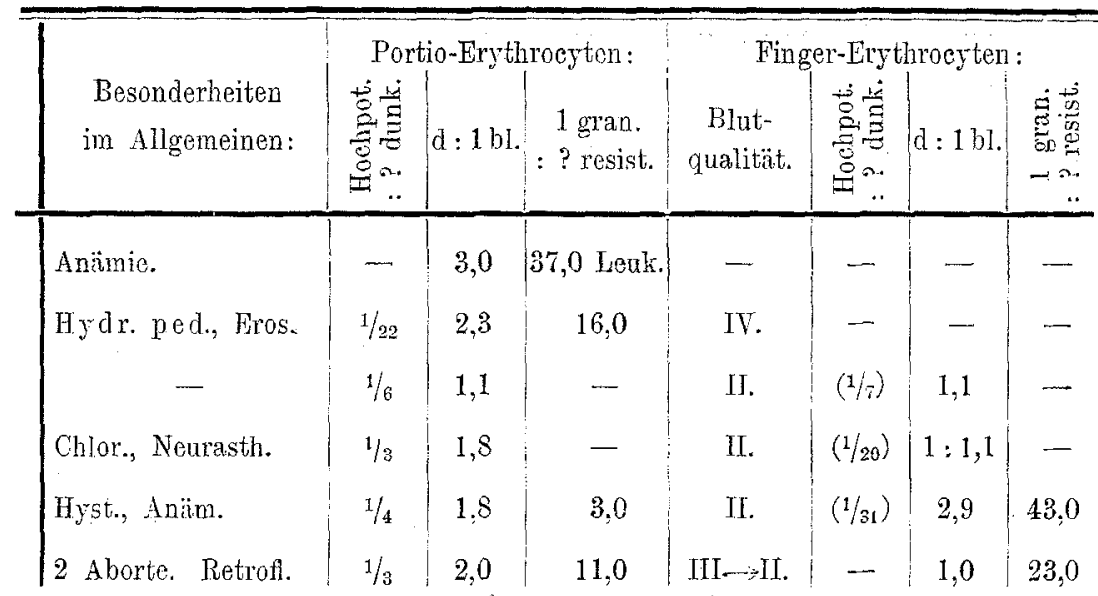

I, 3127. Pelveoperitonitis: Gruppe I, 3060, 3127.

\begin{tabular}{|l|c|c|c|c|c|c|c}
\hline & $(1 / 23)$ & 2,3 & 11,0 & III-3II. & $(1 / 60)$ & 3,0 & 12,0 \\
Hyst., Chlor. & - & 7,6 & 7,8 & - & - & - & - \\
Fitwas Anämie. & - & 5,3 & 23,0 & II. & - & 3,0 & -
\end{tabular}

2268a, 3090. Metritis: Gruppe V, 3070, 3039, 2744, 2486.

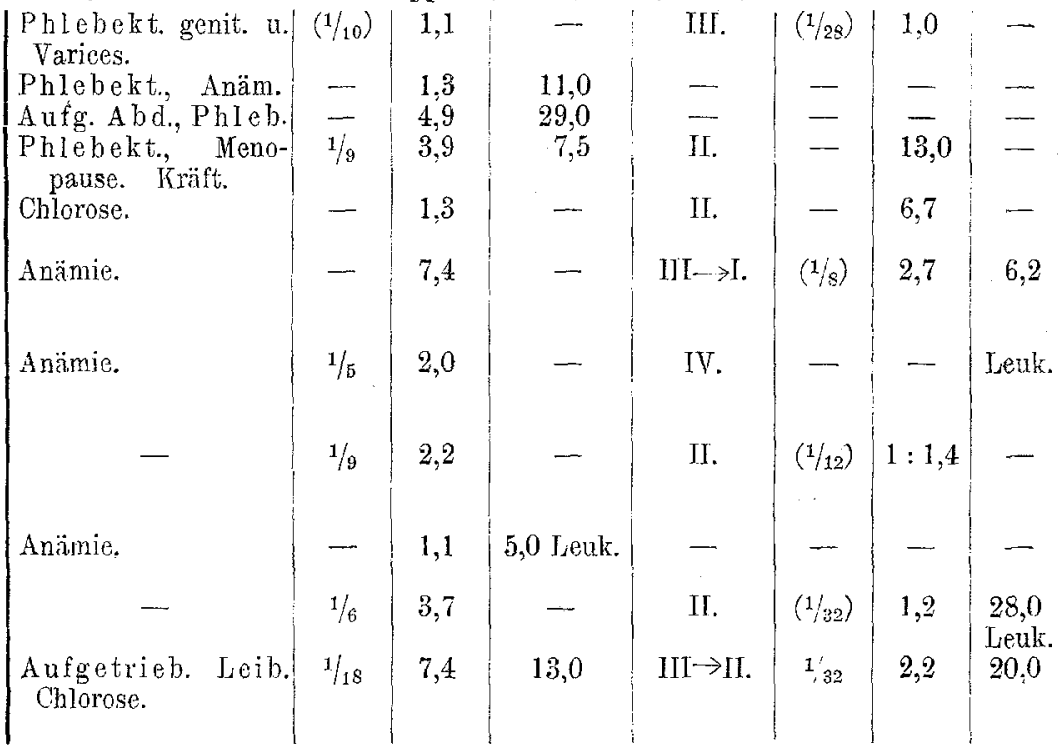

dürfte wohl selbst wieder auf eine seröse Durchtränkung und Ernährungsstörung der elastischen Gewebe zurückzuführen sein, also möglicherweise - ein Circulus vitiosus - auf eine primäre, aus der Schwangerschaft übernommene Gefässstörung, weshalb wir 
diese Vorgänge vorwiegend bei Nichtstillenden und bei Fraven mit schlaffen Unterleibsorganen zu sehen bekommen.

Eine besondere Stellung nimmt bei dieser Gruppe die Metritis chronica subinvolvirter Uteri ein:

Die "Metritis chronica" erweist sich hier als eine Fortsetzung der Subinvolation, da sie keine Reizmomente in der Blutmischung, sondern nur eine weitere Steigerung der passiven Gefässerweiterung erkennen lässt (es fehlen die höherpotenzirten Elemente einer activen Congestion; hingegen finden wir fast ausschliesslich Stase mit oder einfache Congestion, ausnahmsweise nur die Letztere).

Damit sind wir auf die puerperalen Verhältnisse zu sprechen gekommen. Wie die Blutmischung sich während Gravidität, Partus, Puerperium, ferner beim Abortus verhält, habe ich (14) auf der Karlsbader Naturforseher- und Aerzte-Versamml. skizzirt ${ }^{1}$ ). His interessirt an dieser Stelle zu erfahren, dass (auf Grund von э2 Fällen) bei dem geschwängerten retroflectirten und descendirten Uterus sich die höher potenzirende Wirkung der Blutmischung der Retroflexion mit der Schwangerschaft accumulirt und dass erst bei Circulationsstörungen incarcerirter Uteri die Erscheinungen der Stase ausgeprägt werden.

Hämatologische Studien der verschiedenen mit dem Descensus der inneren Genitalien in keiner directen Zusammengehörigkeit stehenden Factoren, durch welche wir den Descensus complicirt finden können, anzustellen, hat nur den Sinn, dass wir die Mischblutbefunde hinsichtlich derartiger Combinationen richtig einschätzen lernen; das reine Bild der letzteren für: sich erhalten wir dadurch natürlich nicht. So geht es vor allem mit der echten Metritis chronica bei dem Descensus. Rein entzündliche Erscheinungen treffen wir bei der Blutuntersuchung solcher Fälle selten, was die Leukocytose des Portioblutes anlangt. Diese ist hier, soweit die cosinophilen Zellen in Betracht kommen, bis auf 4 Fälle geringfügig, und auch bei diesen 4 Fällen traten sie nur recht vereinzelt (im Gesichtsfeld bei 300 facher Vergrösserung) auf; polynucleäre Leukocyten wurden noch viel seltener angetroffen. Anders steht es mit den Erythrocyten; hochpotenzirte Formen treten meist schroff ohne Vermittelung einer einfachen Congestion neben der ebenso häufig

1) Das inzwischen weiter angewachsene Beobachtungsmaterial, welches die damals mitgetheilten Beobachtungen theils bestätigt, theils erweitert, gelangt demnächst zur Veröffentlichung. 
vorhandenen Stase auf. $W_{0}$ in seltener Weise die einfache Congestion mit oder ohne Stase oder die letztere allein auftritt, da handelt es sich um Subinvolution des Uterus und da ist der Charakter der Metritis in den meisten Fällen kein bakteriell entzündlicher, vielmehr die Begleiterscheinung der mangelhaften Rückbildung.

Was Adnexentzündungen und Pelveoperitonitis chronica anlangt, so ist, je nach dem Stadium, damit Congestion oder Stase verbunden. $\mathrm{Zu}$ berücksichtigen ist in der Aetiologie, ob, da die Entzündungen gewöhnlich älter als der Descensus sind und da der letztere zuweilen plötzlich entstanden ist ohne Puerperium und ohne Pression eines entzündlichen Adnextumors (z. B. bei Pelveoperitonitis tubere.), ob nicht gerade hier die Hyperämie (z. B. durch collaterales Oedem), nachdem sie die Ligamente ihrer Flasticität beraubt hat, Ursache des Descensus wird, so dass die in $20 \mathrm{pCt}$. aller Prolapsfälle gefundenen inveterirten Entzündungen (nach Küstner [4]) doch ätiologisch den Senkungsvorgängen näher stehen, auch ohne Heranziehung des rein mechanischen Momentes (Küstner [4]), als jetzt angenommen wird. Gerade bei tuberculösen peritonitischen Exacerbationen habe ich diesen Eindruck gewonnen.

In der Literatur finden sich auch hierher gehörige Fälle beschrieben, freilich ohne eine derartige Dentung, so von Schuh (aus dem Jahre 1860): completer Uterusvorfall bei 22 jähr. Mädchen, Nullip., nach Bauchfellentzündung; das Collum war hypertrophirt, Douglas vertieft. Eine vorher vorhandene Schwäche des Bandapparates muss vorausgesetzt werden, weshalb unter solchen Fällen schwindsüchtige, schmächtige, elènd ernährte Nulliparae fast ausschliesslich vertreten sind. A. Martin (38) führte in seinen Auslassungen ïber sein Referat die Tuberculose als ätiologisches Moment für den virginellen Uterusprolaps an.

Der "stark aufgetriebene Leib" obne entzündliche Ursachen, welcher ja gewöhnlich mit Menstrualstörungen einhergeht, beeinflusst die Blutmischung in der Gebärmutter eher zu Gunsten der arteriellen, sogar recht activen Congestion, als der venösen Anschoppung. Hingegen finden wir letztere leicht begreiflicherweise vorherrschend stets bei Phlebektasien der inneren oder äusseren Genitalien, oder sogar, wenn sie hier fehlen, in den Fällen, welche Varicen an den Schenkeln oder Hydrops der Füsse (ohne Nieren- oder Herzerkrankung) aufweisen. Je nach der Art der Combination treffen wir, aber immer nur neben der Stase, Congestionen an (Elongatio colli, Gravidität). Während hier: also die venösen Gefässe die Transsudation veranlassen, geschieht dieses bei der allgemeinen Auftreibung des Abdomen durch Dilatation der arteriellen Capillaren, durch Congestion.

Die excessive Ausübung...sexueller Perversitäten beeinflusst 
die Blutmischung der Gebärmutter ähnlich wie die Subinvolutio uteri: arterielle und venöse Hyperämie neben cinander, und zwar offenbar beide durch Dauererschlaffung (einfache ursprünglich active, allmählich dauernd passive Congestion und Stase). Zu vergl. Koblanck (31) hinsichtlich der Folgen der Masturbation, auch Beigel's Bemerkungen über Onanie in den Klöstern als Ursache des Vorfalles.

Für unsere Betrachtungen, welche die primäre Hyperämic bei den Frühstadien des Descensus im Auge haben, sind die Fälle von incompletem und completem Prolaps belanglos, weil die secundären und eircumscript entzündlichen Erscheinungen zu sehr in's Vordertreffen rücken. Bald herrscht in Folge dessen die Stase, bald die Erschlaffungseongestion, bald die active Congestion ror.

Was endlich die für unsere Therapie wichtigen Folgen der fixirenden und hebenden Operationen, sowie der reponirenden und retinirenden Pessarbehandlung anlangt, soweit die Mischblutverhältnisse mit der neuen Lage und Haltung der Gebärmutter in Parallele gesetzt werden, so geben dieselben etwa folgendes Bild.

Wo vorher Stase vorhanden war, wurde dieselbe nach der Reposition und Retention in den meisten Fällen verringert weniger constant der Afflux hochpotenzirter Erythrocyten die einfache Congestion wurde in dieser Hinsicht weniger beeinflusst - , derart, dass

von 22 Fällen mit 10mal Hochpotenz, $10 \mathrm{mal}$ einf. Cong. u. Lömal Stase, fast unverändert

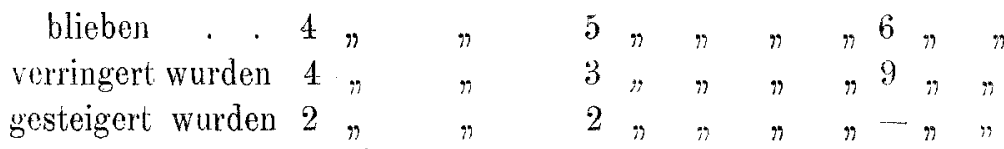

Die Abnahme der venösen Ansehoppung, möglicherweise auch der einfachen Congestion, wenn es sich um dauernd mangelhaft contrahirte Arterien handelt, zufolge der Pessar-Behandlung, dürfte wohl auch auf die theilweise Behebung der secundären Blutcirculationsstörung bezogen werder können.

Anders könnte es mit der doch anscheinond häufigen Abnahme der Zufuhr höher potenzirter Elemente liegen. Indessen ist die Abnahme sehr inconstant, und damn sehen wir ihr Auftreten auch stark abhängig von den Begleitmomenten, entsprechend den Beobachtungen, die wir im Laufe des Aufsatzes kennen gelernt haben. Bs ist freilich ron mir erst in letater Zeit auf diesen Punkt ge- 
achtet worden; ich werde mehr Material sammeln. Vorläufig lässt sich nur so viel sagen, dass die retinirende und fixirende Behandlung bei Descensus (nicht Prolapsus) uteri einen wesentlicheren, aber auch nicht einmal constanten, Einfluss auf die Blutmischung nur hinsichtlich der secundären Circulationsstörungen hat. Wenn sich diese Beobachtung weiterhin bestätigt, so haben wir damit eine weitere Stütze für unsere hier gewonnene Ansicht, dass die schon bei Frühstadien des Descensus beobachtete Hyperämie eine congestive, eine primäre, eine active ist, erhalten. Aber auch eine noch energischere Betreibung der Therapie in anderer Richtung wird dadureh inaugurirt, nämlich sehon von dem Momente an, da der operative Eingriff eine Richtigstellung der Lagerung der inneren Theile erzielt hat, oder andererseits en er: gisch von dem Momente an, da die Disposition zum Descensus erkanntist, - hydrotherapeutische, diätetische und gewebstonisirende (local Glycnrin) Maassnahmen zu treffen unter Hinzuziehung des galvanischen Stromes, von dessen consequenter Application Verf. auch und zumal nach Operationen mit schlaff und succulent verbliebenen Scheidenwandungen oder Bandapparaten, günstige Frfolge zugleich mit endgültiger oder völlig zu Ende geführter Beseitigung der Beschwerden gesehen hat. Jetztere sind in solchen Fällen mehr von der Circulationsänderung als von der Lageverbesserung allein abhängig; nervöse Erscheinungen nicht nur subjectiver, sondern auch objectiv trophischer Natur sind hier wohl ausnahmslos nachweisbar.

Al dieser Stelle ist der Wirkung einschnürender oder zu weiter Pessare bei sehr schlaffen Weichtheilen, insbesondere bei schlaffer Collamwand, zu gedenken, wie ich dieselbe früher als, arteficielles Ektropium" beschrieben (22). Hier gleitet der Uterus in den Ring hinein; durch die Retraction, welche die äusseren Jängsmuskelfasern vom Scheidengewölbe her über den Ring hinweg auf den nicht lacerirten, wohl aber mit einer elasticitätslosen Ringsfaserschicht umzogenen äusseren Muttermund ausüben, beginnt der letztere mehr und mehr zu klaffen und sich mit der vaginalen Fläche der Portio um den Ring nach unten hin herumzulegen. In demselben progressiven Maasse dieses Vorganges schwillt die Portio an; die Cervicalschleimhant wird invertirt und beginnt in vernachlässigten Fälen papilloid zu werden und stark schleimig zu secerniren. In solchen Fällen erzielt die Blutuntersuchung stets hochpotenzirte Congestion and daneben Stase oder einfache Congestion. Hier sind vor Allem Ringpessare zu vermeiden.

Whe wir uns die Ergebnisse dieser Arbeit noch einmal kurz vorführen, ist es ebenso sehr von rein wissenschaftlichem wie von practischem Interesse, uns an der Hand des seither Bekannten 
und besonders durch die werthrollen langjührigen Bier'schen Untersuchungen bekannt Gewordenen auf dem Gebiete der "Hyperämie" eine Deutung unserer hier vorgeführten Beobachtungen zu verschaffen.

Die Diagnose "Hyperämie“, welcher Art anch immer, für je einen hämatologisch untersuchten Fall zu stellen. liess ich mir nicht aus einer einfachen $Z$ ählung der dunkel- und hellgefärbten Erythrocyten und deren Frequenzverhaltniss angelegen sein, sondern, wie oben schon bei der Besprechung der tinctoriellen Verhältnisse angedeutet, ans einer Reihe Factoren: Intensität der Gesammtfärbung mit besonderer Berücksichtigung jener stark gefärbten Erythrocyten, die icls im engeren Sinne als "jodophile" beschrieben und als "hoherund hochpotenzirte" bezeichnet habe, Vorkommen der wenig resistenten granulirten und entfärbten rothen Blutkörperehen, die häufig nur noch aus einer dorchsichtigen, von einem stark lichtbrechenden Rande umgebenen Scheibe bestehen, Yorkommen von A bschnürungen, ferner von kürnigem Detritus, dessen Färbbarkeit und den in ihm nicht selten zusammengeklebt and mit heukocyten untermischt liegenden Erythrocytenhaufen.

Diese Beobachtungen des Portio mischblutes werden mit den gleichen aus dem Iinger beerblut gewonnenen verglichen ind hierdurch sowohl, wie anch durch Inbetrachtziehung des allgemeinen Kräftezustandes, etwaiger anderer organischer Leiden (Herz, Leber, Nieren, Darm, Entzündungen, Varicen, Neurasthenien u. s. w.), etwaiger Schwangerschaft und (nicht zu vernachlässigen!) der Nähe des Periodentermines, wird ein genauer Vergleich zwischen allgemein constitutioneller Blutbeschaffenheit und specieller Genitalversorgung erzielt. Ueber die Technik und Deutung von Einzelbefunden werde ich an anderer Stelle eingehend sprechen; das sei nu. hier noch erwähnt, dass die Blutprobe unmittelbar aus der Einstichstelle in die isotonische Lösung eingesogen werden muss.

Hinsichtlich der Beurtheilung der Färbung und der Frequenzverbältnisse müssen natürlich Vorstudien an einwandlos gesunden Genitalien und kräftigen Individuen in deren verschiedenen physiologischen Etappen (sub mensibus, unmittelbar ante et post menses, Periodenintervall, Graviditas u. s. w. in verschiedenen Monaten, bei Selbststillen des Kindes, Nichtstillen u. s. w., Klimax und Menopause) gemacht werden. Die Beurtheilung der Färbung lernt man rasch durch Erfahrung und Vergleichung. Was die Zablen anlangt, so mag die Frequenzproportion der dunklen zu den hellen Erythrocyten im physiologischen Wittel zwischen 2-3:1 liegen. Indessen besteht hier keine Constanz; das Urtheil ist erst uach Zuratheziehung aller obigen Factoren abzugeben. Der Begriff "normal" ist vielleicht nirgends schwieriger gu definiren als in der Hämatologie.

Die Befunde von insgesammt über 5000 Untersuchungen haben mir aus der Berücksichtigung obiger Factoren 26 Formeln ergeben, deren Werthigkeit hinsichtlich der Miscbblatqualitat sich ungezwungen in 4 Gruppen (in den Tabellen als $I$ bis $I V$ bezeichnet) einordnen liess (I. Hypertonie, II. Isotonie, III. sehwache Isotonie, IV. Hypisotonie und Hypotonie).

Die Qualitat des Erythroeytenzuflusses. wurde mit "Hoch. 
und Höherpotenz" der sehr stark und stark jodophilen Blutkörperchen, mit "einfacher Congestion", wenn die einfach dunklen an Zahl dem Mittel entsprachen oder über dasselbe gingen, und endlich mit ,Stase" bezeichnet, wenn die blassen oder gar die granulirten und entfärbten unter Mittel oder in der Ueberzahl waren. Zu betonen ist noch einmal, dass es sich hier um Beobachtung der Blutmischung, nicht so sehr der allgemeinen Blutqualität handelt.

Der Begriff "Stase" ist klar; es handelt sich um die venöse Hyperämie, welche auch als „passive" bezeichnet wird; sie wird unter Erschlaffung der Wandungen der Venenäste und Venencapillaren durch Rückstauung hervorgerufen. Der Blutstrom ist verlangsamt.

Dieser gegenüber wird, so auch jetzt noch von Bier.(23), die "active Hyperämie" gestellt, welche durch die central ausgelöste Herabsetzung des vasomotorischen Arteriendruckes oder durch dio - gleichfalls central ausgelöste — Dilatation der Arterien zur "Congestion" führt. Je stärker (innerhalb bestimmter Grenzen) die Erweiterung, je mehr die Hauptzufuhrarterie eines Organes an derselben participirt, desto (meistens) schneller und grösser der Blutstrom, desto weniger werden die einzelnen Blutkörperchen in dem Organ abgenutzt, desto intensiver behalten sie ihre Färbbarkeit in der Jodjodkalilösung. Die weniger abgenutzten, jodophilen Erythrocyten behalten also eine höhere Potenz; je zahlreicher sie im Mischblute vorkommen, desto vollkommener ist die active Hyperämie, die Congestion, die Ueberschwemmung mit arteriellem Blute. Sie kann noch dadurch gesteigert werden, wenn der Blutdruck trotz Erweiterung dieser Organgefässe erhöht und dadurch der Blutstrom auch noch stark beschleunigt ist. Aber es giebt noch eine andere Möglichkeit, und darüber belehrt uns im concreten Falle die der Fingerbeere entnommene Mischblutprobe. Finden wir auch hier die hochpotenzirten Erythrocyten in mehr oder weniger grossen Mengen, so handelt es sich, wenn keine Circulationsstörungen vorliegen, um eine Steigerung der Jodophilie des Gesammtblutes (bei Gravidität z. B.) oder um eine mehr oder weniger reichliche physiologische Beimengung von Regenerationsformen oder um eine Blutanomalie.

Von einer actjven Hyperämie möchte ich im Anschluss an derartige Untersuchungen nur dann reden, wenn hochpotenzirte Erythrocyten in grösseren Mengen (etwa 1/10 oder mehr von der Summe der dunkeltingirten r. Bl. K.) vorkommen oder auch, wenn in Abwesenheit solcher die Gesammtmenge der dunkelgefärbten Archiv f. Ggnäkologie. Bd. 71. H. 1. 
r. Bl. K. auffallend stark (dunkelbraun ev. mit röthlichem Beitone) tingirt ist, während $z$. B. die Fingermischblutprobe keine hypernormale Eigenschaften aufweist.

Nun giebt es, ebenfalls nach diesen Untersuchungen, eine andere Art Blutmischung, die nur als congestive gedeutet werden kąnn, zumal da der makroskopische Befund gleichfalls auf eine solche hindeutet: Die Zahl der dunklen Zellen ist vermehrt, nicht aber deren Färbbarkeit, - im Gegentheil, es kann Letztere sogar herabgesetzt sein gegenüber derjenigen, z. B. des Fingerbeerblutes.

Die Deutung sei folgende: Diese arteriellen Erythrocyten sind in vermehrter Menge dem Mischblute beigegeben, wurden aber stärker ausgenutzt. Mithin sind die Arterien erweitert, der Blutstrom aber nicht in den zuführenden Stammgefässen, sondern nur im Capillarsystem vergrössert und erheblich verlangsamt. Beides lässt sich nur vereinigen, wenn das zuführende $S$ tammgefäss nicht erweitert ist, wohl aber die kleineren Aeste und das arterielle Capillarnetz im Organe. Auch das venöse Capillarnetz muss erweitert sein. Der Abfluss in den nicht erweiterten Stammplexus hingegen kann auch verzögert sein. Auf diese Weise entsteht in dem gesammten arteriellen und venösen Capillar and Kleinast-System eine Stromverlangsamung, die noch primär oder jedenfalls secundär in circulo vitioso dadurch vermehrt wird, dass zu Folge der in das Bindegewebe hinein stattfindenden Transsudation abwechselnd theils eine Herabminderung der Elasticität and damit des auf den Gefässen lastenden Gewebsdruckes. mithin Vermehrung der Transsudation stattfindet bis zum Eintreten eines Staungsdruckes in dem Bindegewebe, welcher durch den Lymphabfluss allein nicht bewältigt wird und zum Rückdruck gegen und in die Gefässe hinein führt [Landerer (2), Klemenciewicz (24)]. Solche Zustände können nicht dur'ch eine abnorme Beschaffenheit des Blutes, sondem durch eine dauernde Erschlaffung der Gefässwandungen und gleichzeitigen Elasticitätsschwund des Bindegewebes hervorgerufen werden. Fine derartige Prädisposition können wir uns durch ein Persistiren der Verhältnisse, in welchen sich die Genitalien während der Schwangerschaft befinden (Ligamente, Uteruswand, paravaginales Gewebe), erworben vorstellen. In der That bietet die Subinvolutio uteri auch in Gemässheit der Blutuntersuchungen ein solches Bild: „einfache Congestion" und Stase, eventuell wemn das Line oder das Andere überwiegt, das Endergebniss der Ersteren oder der Letzteren allein.

Diese neinfache (nicht hochpotenzirte) Congestion" repräsentirt also einen Zustand der Dauererweiterung durch Erschlaffung, also auch eine passive "arterielle" Hyperämie, im Gegensatze zu der gewöhnlichen passiven venösen Hyperämie; man könnte vielleieht von einer "passiven Congestion " reden, insofern als die herbeigeleiteten Blutkörperchen bereits in den arteriellen Capillaren eine Stagnation erleiden und insofern als die Vergrösserung des 
Stromes nicht durch die grosse Menge zeiteinheitlich herbeigeführten Blutes, sondern durch Aufstaung in erweiterten Capillaren hervorgerufen wird. Von dem Verhalten der Venen kann es abhängen, ob nicht auch der hochpotenzirte Zustrom zur Stauung führt.

Bier beschränkt zwar die Begriffe "active und passive Hyperämie" auch nicht unbedingt auf arterielle und venöse Blutansammlung, $d . h$, vermehrten $\mathrm{Zu}$ - bezw. verminderten Abfluss, indem er betont; - diese $\mathrm{Be}$ zeichnungen "decken sich nur im Grossen und Ganzen und im Allgemeinen", - er führt aber als Beispiel nur die Staungslunge an, in der sich bei incompensirten Herzfehlern allerdings das Blut aus den Lungenvenen zurückstaut; gleichwohl ist dieses Blut aber 0 -reich und $\mathrm{CO}_{2}$-arm, also qualitativ arterielles Blut.

In dem von mir angeführten Mischverhältniss tritt freilich häufig ein Stadium ein, wo man sowohl klinisch wie auch experimentell nicht mehr sagen kann, ob man die Hyperämie arteriell oder venös nennen soll; praktisch bat das ja anch gewiss seine Bedeutung, aber wissenschaftlich interessirt uns vor Allem die Genese, und da ist es wichtig, an die geschilderten Uebergänge zu denken. Bier (23) deutet darauf - allerdings wieder vor Allem mit Rücksicht auf die Entzündung hin, indem er sagt: „Die verschiedenen Arten der Hyperämie kann man garnicht streng auseinander halten, da sie unmerklich ineinander übergehen, zumal es der Körper versteht, den ursprünglich schnell fliessenden Blutstrom durch in ihrem Wesen unbekannte Reize, vor Allem den Entzündungsreiz, in einen langsamen zu verwandeln."

Die Vergrösserung des Blutstromes (active oder functionelle Hyperämie) meist mit, seltener ohne Beschleunigung (in Abbängigkeit von dem Blutdruck bei erweiterten Gefässen) sehen wir in Begleitung von Functionen (Drüsen-, Darm-, Muskelthätigkeit), bei Resorptionen, im Beginn einer Entzündung und unter dem Einflusse von gefässdilatirend wirkenden Nerven bei glattem venösem Abflusse auftreten, - die Verlangsamung (Verminderung des venösen Abflusses, passive oder Stauungs-Hyperämie) bei Beseitigung von Schädlichkeiten, bei dem. Aufbau von neuem Gewebe, so also auch im weiteren Verlaufe von Entzündungen und bei der Wundheilung.

Die während der Schwangerschaft eintretende ödemisirende Hyperämie der Genitalien bringt alte Eiterherde zur Resorption und lockert und löst Narbenmassen auf; diese Hyperämie ist sowohl arterieller wie venöser Natur, und nach Bier wirken Beide auflösend, während die Erstere allein resorbirend wirkt. Letztere Angabe stimmt zu meinen früheren Beobachtungen am Krankenbette wie dureh Blutuntersuchungen, dass z. B. die enorm und auf viele Wochen hin activ hyperämisirende Atmokausis alte Adnexeiterherde, ferner Myome in kurzer Zeit zur Resorption bezw. Letztere zur erheblichen. Verkleinerung zu bringen vermag. Aber auch das ergeben die Blutuntersuchungen, dass die in graviditate tiefblau gefärbten Genitaltheile mit hoch- und hö chstpotenzirter 
Congestion neben mehr oder minder bedeutender Stase versehen sind.

In dem post puerperium mangelhaft involvirten Uterus, zumal nach Aborten, finden wir selten hochpotenzirte Congestion, wohl aber die passive arterielle Form und die Staung: in der That kommt es auch nicht zur Resorption der Gewebsflüsigkeit; denn der Uterus bleibt verdickt und schlaff; die Muscularis bleibt brüchig und weich und histologisch finden wir die Muscularisfasern auseinandergedrängt durch eine flüssige Masse, die elastischen Fasern schollig und hyalin zerfallen und späterhin durch ödematöses faseriges Bindegewebe substituirt. Dieselbe "passive arterielle Hyperämie" stellten wir im Gefolge von sexuellen Perversitäten fest, neben Stase.

Die arterielle Erschlaffungshyperämie tritt an häufigsten neben der Stase oder bei solchen Gonitalleiden auf, bei denen die hochpotenzirte active Congestion selten ist (vergl. Tab. II, Descensus und Desc. ut. subinvoluti), oder bei ersichtlichen Circulationsstörungen, so bei Retrofl. ut. gravidi incarcerati, Prolapsus uteri, Einklemmung des Collum im Pessar u. ä.

Wenn wir so gezwungen sind, die "passive Congestion" in dem eben ausgeführten Sinne anzuerkennen, und ebenso bestimmte Schädigungen scitens derselben, welche an diejenigen der Stase erinnern, - wollen wir andererseits untersuchen, ob wir einen Einfluss der hochpotenzirten activen Congestion auf die Ernährung und das Wachsthum der Genitalgewebe im Anschluss an unsere Blutuntersuchungen feststellen können.

Es ist ja a priori denkbar und wahrscheinlich, in der That aber weder empirisch noch experimentell für eine Mehrheit der Fälle erwiesen, dass die active Hyperämie eine Ueberernährung und dadurch eine Hypertrophie von Geweben und Organen zu Stande bringt. Für die Frage nach der Genese der Cervixhypertrophie wäre diese Erzielung einer festen Ansicht ron Bedeutung:

Der Beurtheilung der einschlägigen Beobachtungen muss man stets den Satz zu Grunde legen, dass ein nicht functionirendes Organ, eine nicht functionirende Zelle der Atrophie, der Entartung verfällt, dass umgekehrt nur eine functionirende Zelle, ein functionirendes Organ anwachsen kann; der "functionelle Wachsthumsreiz" kann nicht durch einen starken arteriellen Blutaflux beim Ruhezustande des betr. Organes ersetzt werden; die Congestion 
unterstützt nur das Wachsthum eines Organes, wenn es arbeitet; ohne die Congestion würde der von der Function ausgehende Wachsthumsreiz aus Mangel an Aufbaumaterial zu keiner oder ungleich geringerer Vergrösserung oder Vermehrung führen.

Ich habe absichtlich nur von der Frage der Einwirkung der activen, der rein functionellen Hyperämie auf das Wachsthum gesprochen, da es sicher ist, dass die venöse Hyperämie an sich einen Wachsthumsreiz repräsentirt, wenngleich die hypertrophirenden Organe sich nicht dauernd aus functionskräftigem Materiale aufbauen; immerhin kommt es zur Vermehrung des ursprünglichen, also gleichartigen Zellmateriales, z. B. Muskelhypertrophie bei und nach Phlebothrombose, wobei die Muskelproben aber meist bleich, blutleer, weicher, die einzelnen Muskelfasern bypertrophisch, aufgequollen, öfters mit fettiger und wachsartiger Degeneration behaftet gefunden worden sind. Da handelt es sich also offenbar um einen abnormen, um einen toxischen Wachsthumsreiz Seitens der venösen Hyperämie, der schliesslich nur zur lipomatösen Degeneration des eigentlichen functionirenden Gewebes führt.

Hingegen finden wir in allen Organen (ebenso bei inneren Stauungsorganen), dass meist bei passiver, aber auch bei activer Hyperämie eine Hypertrophie der Deck-, Bindeund Stützgewebe eintritt, wodurch Roux's Satz ebenfalls aus der Pathologie bestätigt wird, dass "nur Organe mit passiven Functionen durch eine Vergrösserung der Nahrungszufuhr ohne weitere Reize zu vermehren sind;" Bier (23) sprach dasselbe aus unter der Bezeichnung ,anspruchslose und andererseits höher organisirte Gewebe".

Daraus erklärt es sich, dass einerseits lange fortgesetzte Behandlungen und Experimente mit activer Hyperämie (Heissluftbäder) noch nie eine Hypertrophie von Muskeln, Nerven, secernirenden Epithelien u. s. w. haben zur Beobachtung gelangen lassen, dass andererseits beim Kaninchen die bald durch Excision eines Sympathicusstückes, bald durch locale Temperaturerhöhung erzeugte dauernde Congestion einer Kopfhälfte constant zur Hypertrophie (23) oder zur schnelleren Wundheilung (48) des mitbetroffenen Ohres, also eines im Wesentlichen aus Deckund Stützsubstanzen bestehenden Organes, führt, und dass ebenso beim Menschen die Behandlung mit activer und noch mehr mit Staungshyperämie zur Hypertrophie von Haut, Bindegewebe (Elephantiasis) und Knochen, wenn auch nicht constant, führt. Wahrscheinlich scheint mir der Zusammenhang wohl so, dass die Congestion die eigentlich aufbauende Staungshyperämie, wie bei den Entzündungs- und Wundheilungsprocessen, einleitet; dass die Letztere also das eigentliche Agens ist, wie uns ja auch 


\section{Schaeffer, Ergebnisse hämatologischer Untersuchungen für die}

Bonnet's Untersuchungen gereigt haben, dass die Entwicklang des Eies zum Embryo, des Embryos zum reifen Kinde nur unter dem Einflusse einer intensiven Staungshyperämie vor sich geht: Placentarsinus, Oedem der Placenta, langsame Strömung im fötalen Blutkreislaufe, Versorgung der Frucht mit nirgends ganz arteriellem Blute (im Sinne des Erwachsenenblutes).

Bei dem Vorfalle innerer Genitaltheile beobachten wir dreierlei Formen der Volumzunahme: 1. die rein ödematöse Schwellung, welche nach Reposition zurückgeht, -2 . die Dickenzunahme, welche erst nach langer Zeit der Retention der Scheidenwand und des vorgefallenen Gebärmuttertheiles zurüekweicht und welche theils in Epidermoidalisirung der Schleimhaut, theils in dauernder Erweiterung der Gefäss- und Saftbahnen und in Elasticitätsschwund und Schwellung der einzelnen Bindegewebs- und glatten Muscularisfasern, theils in Hypertrophie des Bindegewebes besteht, - 3. die Längenzunahme des Collum uteri oder nur der Portio vaginalis, welche in einer thatsächlichen primären „idiopathischen" oder durch Subinvolutio puerperalis (also jedenfalls unabhängig ron dem Vorfall) erworbenen Gewebshyperplasie besteht und deshalb trotz der Retention nicht verschwindet.

Die 2. Form entsteht offenbar durch den Reiz der zum Theil venösen Hyperämie, später in den oberflächlichen Partien wohl auch anf die rein mechanischen und (bei Exulcerationen) bacteriellen Schädigungen hin; sie ist deshalb mit Hinsicht aul den Vorfall secundärer Natur.

Hierher gehört als besondere Abart die Erzeugung eines Erschlaffungsektropiums durch Einlegen eines Ringpessars bei seh ${ }^{\circ}$ schlaffer Collumwand und Descensus uteri. Die dem Auseinanderweichen der Huttermundslippen (ohne Lazeration) folgende allmähliche papilloide Wucherung der ektropionirten Cervicalmucosa ist im Wesentlichen durch die Hyperämie hervorgerufen (vergi. Verf.'s Beschreibung [22] des "arteficiellen Ektropiums").

Am meisten interessirt uns hier die 3. Form. Die Blutuntersuchungen ergaben nun bei uncomplicirter Elongatio colli eine Paarung des Descensus eines derartig hyperplastischen Organes mit dem Auftreten von bochpotenzirter plus einfacher Congestion ohne Stase. Letztere fanden wir nur jenseits der Menopause oder bei Phlebektasien u. ä. In uncomplicirten Fällen berrscht also die active Hyperämie unbedingt vor. Bei gleichzeitig hypoplastischen Gebärmutterkörpern ist ebenfalls - im Gegensatze 
Aetiologie und Pathologie der Senkung der weiblichen Genitalien. 215

zu den übrigen Fällen der Infantilismus-Gruppe - ein Vorherrschen der activen Hyperämie bemerkenswerth!

Das Gepartgehen der Elongatio colli mit einer an anderer Stelle geschilderten so auffallenden Erscheinung wie der activen Hyperämie veranlasst uns, Beides entweder auf eine gemeinsame Ursache oder, was wohl noch wahrscheinlicher ist, die Hypertrophie und den thatsächlichen Descensus zusammen zunächst auf die Congestion zurückzuführen. Die Congestion ist deshalb als etwaige secundäre Erscheinung so unerklärlich, weil weder eine Entzündung vorlag und noch weniger das Collum uteri ein functionskräftiges Organ ist; es besteht ja fast ausschliesshich aus Bindegewebe. Aber das dürte gerade die Möglichkeit seines excessiven Wachsthums abgeben. Die Congestion betrifft natürlich den ganzen Uterus, dessen active Organmasse aber, die musculäre Wand des Corpus uteri nach den obigen Auseinandersetzungen der Congestion allein nicht als Wachsthumsreiz zu folgen vermag, dessen passive Gewebe aber, welche zwischen den Muskelfasern. und submucös und subserös und intraligamentär liegen, vor allem aber gerade die unteren Gebärmutterabschnitte bilden, hierauf mit Hypertrophie zu reagiren vermögen und dieses - bei einer weiteren bestimmten Prädisposition, die ontweder im Blute oder im Gewebe liegen muss und unbekannt ist, wahrscheinlich aber eine Entwicklungshemmung repräsentirt - auch thun. Einerseits kommt die (nicht infectiös entstehende) sog. chronische Metritis unter Bindegewebsneubildung, andererseits die Elongatio colli zustande. Schwerere Circulationsstörungen zumal in späteren Stadien der Gefässerschlaffung führen neben dem ${ }_{n}$ chronischen Uterusinfarkt" Scanzoni's [- Mesometritis chronica (40)] oder der Sklerosis (41) zum Oedem und zur hyalinen Degeneration der Muskelfasern [Myometritis oedematosa (42)], wodurch die Uteruswand butterweich werden kann; den gleichen Zustand können wir aus den gleichen Ursachen nach Aborten Multiparer beobachten. In den meisten Fällen aber nimmt schliesslich die Sklerosis den eirrhotischen Charakter an.

Die active Congestion erzeugt also die bindegewebige Hypertrophie einerseits, den Elasticitätsschwund und die Senkung andererseits; dass bei Nulliparis die invertirte Scheidenwand, das Scbwergewicht und die Richtung des hypertrophirten Collum dieses allein besorgt, ist doch unwahrscheinlich [K üstner's Referat (4)]; wohl wäre in entsprechenden Fällen, vor Allem bei Nulliparis und Virginibus 
darauf zu achten, ob nicht doch wohl noch andere analoge Vorgänge in den Ligamenten etc. Ursache des Descensus sein können, nämlich Hypertrophie der fibrösen. Schwund der elastischen Bindegewebsfasern! In der Bildungshemmung der "tiefen Douglastasche" Freund's und Sellheim's (25) möchte ich ein solches im Verbältniss zu den "activen" Organen hypertrophisebes Product von geringer Elasticität sehen; hinsichtlich der Auffassung des "Tiefstandes des Excavatio vesico-uterina" als einer infantilen Hemmung besteht ohnehin keine Einigkeit zwischen Waldeyer, der sich zuerst so geäussert hat, und Sellheim.

Die Ergebnisse dieser Arbeit sind also folgende:

\section{Beobachtungen :}

1. Die aus der Portio vaginalis (und in jedem Falle vergleichsweise aus der Fingerbeere) entnommenen Mischblutproben lassen in physiologisch isotonischer Jodjodkalilösung untersucht 4 tinctoriell verschiedene Erythrocytensorten erkemen: a) sehr stark tingirte (jodophile) $=$ hochpotenzirte, b) gut tingirte $=$ vorwiegend arterielle, o) schwach tingirte und leidlich resistente $=$ vorwiegend venöse, $d$ ) granulirte und entfärbte von herabgesetzter Resistenz.

2. Hieraus ergeben sich 3 Sorten der Blutmischung: a) active, z. Th. hochpotenzirte Congestion, b) einfache Congestion, z. Th. in Folge von Dauererschlaffung der Arteriencapillaren (und kleineren Aeste) als eine Art "passive Congestion", c) venöse Stase = gewöhnliche „passive Hyperämie".

3. Die "nactive (oft hochpotenzirte) Hyperämie" wurde ïberwiegend gefunden bei

a) einfacher Retroversio-flexio uteri (sine descensu),

b) bei leichtem, d. h. beginnendem Descensus uteri (anteversi),

c) bei Inversio vaginae (meist Cystocele sine descensu uteri),

d) bei Descensus uteri retroflexi (combinirt mit Stase),

e) bei Elongatio colli.

f) Gravidität des descendirten retroflectirten nicht incarcerirten Uterus.

4. Die "venöse Stase" wurde überwiegend gefunden bei:

a) erheblicherem Descensus uteri (retroflexi),

b) Phlebektasiae genitalium,

c) Subinvolutio uteri descendentis, mensium).

d) bei inactivem Organe vielfach (Hypoplasie, Henopause, Suppressio

5. Die "einfache arterielle Erschlaffungshyperämie" (eine Art „passiver Congestion") meist zusammen mit Stase, selten, aber dann typisch, mit aetiver hoehpotenzirter Congestion, ebenso selten alle $3 \mathrm{zu}$ sammen und dann nur bei Combination verschiedener Factoren ( $z$. B. Descensus uteri retroflexi et subinvoluti $u, A$. : :

a) Hypoplasia nteri (Infantilismus) zusammen mit Stase,

b). Descensus bei allgemeiner, nicht entzündlicher ,Auftreibung des Abdomens" (meist ohne Stase).

c) Descensus eines anteflectirten Uterus + Cystncele oder hochgradiger Erschlaffung aller Theile (einf. Cong.). 
d) Descensus uteri retroflexi + Subinvolutio oder Phlebektasien oder Descensus ovar., zugleich mit venöser Hyperämie.

e) Einfache Inversio vaginae bei sehr grosser Schlaff beit aller Theile (vorwiegend einf. Cong.).

f) Oft bei Descensus Seniler oder bestimmter Steriler (zuweilen zusammen mit Stase).

g) Subinvolutio uteri puerperalis, zumal mit nicht infectiöser Metritis chronica (zusammen mit Stase).

h) Perversitäten bei descendirtem Uterus (Onanie, Masturbation, auch langjähriger Coitus interruptus).

i) Prolapsus incompl. et completus (aber wechselnd, je nach den Begleitmomenten bald mit Hochpotenz, bald mit Stase).

k) Bei Retrofl. uteri gravidi incarcerati (zusammen mit Stase).

1) Bei Einklemmung des Collum durch zu enges Pessar oder bei Hindurcbgleiten und Ektropionirung des äusseren Muttermundes durch ein Ringpessar, wenn die Collumwandungen zu schlaff sind ( + Stase).

6. Bei intacter Retroversio-flexio uteri, ohne Subinvolution: Hochpotenz, also active Congestion, - venös (mässig) nur bei gleichzeitiger Cystocele; zugleich mit allgemeiner nicht entzündlicher , A u ftreibung des Abdomen" einfach congestiv (also arterielle Erschlaffung). - Die Retroflexion compensirt bei lebhaft functionirendem oder reagirendem. Organe durch die sie begleitende active Congestion die venöse Stase des erheblicheren Desc. ut. - Die Retroflexion combinirt mit Cystocele steigern sich wechselseitig in ihrer activen Hyperämie.

7. Der einfache erheblichere Descensus uteri meist mit Stase, allein oder mit jedem Grade der Congestion zusammen in Abhängigkeit von den Begleitmomenten, und zwar entweder Hochpotenz + Stase (so bei gleichzeitigen activen Entzündungen, spastischen Contractionen und Retroflexio ut., Desc. ov., ferner in Anfangsstadien des Descensus) -.- oder passive Congestion (bei gleichzeitiger Inversio vaginae, Perversitäten). Bei der Combination Descensus uteri anteflexi + Cystocele wird die passive arterielle Hyperämie vermehrt (also Erschlaffung der Gefässe), während bei Descensus uteri retroflexi + Cystocele die active Congestion nur dann gesteigert wird, wenn es sich um Anfangsstadien handelt.

8. Descensus uteri retroflex i ist gepart mit Hochpotenz + Stase, und zwar je ausgesprochener die Retroflexion ( + Inversio vaginae) und je geringer der Descensus, desto höhere Potenz und desto geringere Stase, an deren Stelle Congestion. Die Combination mit Subinvolution, Phlebektasien, Sterilität, Desc. ov. führt zur Steigerung der Stàse und Hinzutritt der einfachen passiven Congestion (allgem. Gefässerschlaffung).

9. Die Inversio vaginae (Cystocele) nicht Stase erregend (obwoh] combinirt Hochpotenz + Stase), vielmehr hat sie ein die active Congestion erregendes ätiologisches Begleitmoment, wie die Retroflexio ut., zumal in Frühstadien, noch vor dem Desc. ut. - Die Stase des Desc. ut. wird durch die Inversio zu Folge Zuführung böher potenzirter Elemente compensirt. Die Hochpotenz der Inversio vag. wird durch die gleiche der Retroflexion gesteigert, - ferner aber keines: wegs immer gleichzeitig die allgemeine Congestion durch Infantilismus oder Elong. colli oder Metritis oder Puerperium in bestimmten Stadien oder Prolaps. incompl. (senilis).

Die passive Congestion der Invers. vag. wird erhöht durch sehr grosse Schlaffheit, Descensus uteri bei Senilen. 
Die Stase wird vermehrt dureh gleichzeitige Subinvol. ut., Desc: ut. retrofl. (bei Senilen), Phlebekt. oder andere Complicationen neben Desc. ut. retrofl.

10. Subinvolutio uteri, begleitet von passiver, arterieller und venöser, Hyperämie (Erschlaffung aller Gefässe); sie compensirt die Hochpotenz bei Retrofl. ut. und Inversio vag. (bezw. umgekehrt: die Hochpotenz kommt durch Letztere zu der passiven Hyperämie von Subinvolutio ut. hinzu) - accumulirt sich zu Stase bei Desc., Phlebect. Die passive Congestion und Stase können sich wechselseitig paralysiren (gesteigerter Gewebsdruck durch Transsud. und Elasticitätsschwund). - Metritis chron. bei Subinvolutions-Erhöhung der passiven Hyperämie (der allgemeinen Gefässerschlaffung) der Arterien und Venen.

Beobachtet wurden Fälle plötzlicher Erschlaffungsretroflexion mit acutem Uebergang ron der activen zur passiven Congestion.

11. Complicationen des Desc. ut.: Metritis chron. (nicht bakt. entzünd.). "Aufgetriebener Loib" (nicht entzündl.) Phlebect., Varices, Hydrops ped.: stets Stase und daneben Abhängigkeit von Combinationen hinsichtlich der Art der arteriellen Hyperämie. Perversitaten: arterielle und venöse krschlaffmgshyperämie. Prolaps ut.: s. sub Gruppe VI-XII).

12. Graviditat bei Desc. ut. retrot, begleitet durch hochpot. Congestion; nur bei Incarceration oder Abort: Stase. Bei Reposition: einfache Congestion + Hochpotenz an Stelle jener Stase.

13. Elongatio colli: Hochpotenz + einfache Congestion (Stase nur in Nenopause oder bei Phlebect.) - also active Hyperämic.

14. Infantilismus, an sich einfache Congestion + Stase vorherrschend und $z$ war rein bei gegen

a) Retrofl. ut. sine desc. oder + Retention durch das Pessar - hin-

b) Antefl. ut. + Desc. höher potenz., noch mehr + Invers. vag.; hierher auch Fäle relat. Elong. colli bei Hypoplas. corp. ut. - Hochpotenz nur bei uncompl. Retrofl. ut.

15. Retinirende und fixirende Therapie: Aenderung der sec. Hyperämie (passiv), unbedeutend betr. Hochpotenz; Wirkung inconstant, - an constantesten Verminderung der Stase.

Pessarwirkung bei schlaffem Collum: Ektropion arteficiale (sine laceratione), passive arterielle und venöse Hyperämie, papilloide Schleimhauthyperplasie.

\section{Schlussfolgerungen und Thesen:}

I. Die Frühstadien der Senkung, insbesondere Fälle ron Cystocele mit eben beginnendem oder noch nicht begonnenem Descensus uteri, gehen gepaart vorwiegend mit activer hochpotenzirter Congestion, welche Mangels acut entzündlicher Vorgänge zunächst nur als lokalneurotrophische (vasomotorische) Storung aufgefasst werden kann und deren Entstehung jedenfalls im Zusammenhange mit den Eigenthümlichkeiten der Blutcirculation im weiblichen Organismus und Becken gesucht werden muss; inwiefern hier eine allgemeine oder abdominale Verarmung des Organismus, also auch des Blutplasmas (plasmatische Anämie), an Kalksalzen die primäre Ursache sein kann, behalte ich fermeren Untersuchungen vor.

II. Da es böchst wahrscheinlich ist, dass diese active Hyperämie mit Strombeschleunigung schon vor Beginn der ersten Senkungs- 
erscheinungen oder deren Vorläufer (Cystocele, Retroversio uteri) besteht und jedenfalls erstere keine Folge der letzteren sein kann, so ist es denkbar, dass diese Hyperämie die Veranlassung zum Elasticitäts. schwunde (durch Transsudation zwischen die elastischen Elemente der Ligg. cardinalia, des Pericystium und des Subserosium der Excavatio rectouterina-vaginalis) in dem Band- und Haftapparate der Beckenorgane abgiebt und dadurch die Prädisposition zum. Descensus schafft.

III. Als Frühstadien wären uater diesen Voraussetzungen nach den hämatologischen Untersuchungen anzusehen: die Cystocele, die Retroversio uteri, die Elongatio colli, die zu descendiren beginnende Anteversioflexio, seltener Retroflexio uteri, was mit unseren bisherigen Anschauungen, welche gerade in der Cystocele und der Retroversio uteri mechanisch-ätiologisehe Momente für den Descensus sehen, und den klinischen Beobachtungen übereinstimmt.

IV. Die späteren Stadien des Descensus uteri weisen mehr und mehr das Hervortreten der einfachen arteriellen Erschlaffungscongestion (an Stelle der activen hochpotenzirten) und der venösen Hyperämie auf, zumal wenn gepaart gehend mit Subinvolutio uteri, mit oder ohne Metritis (nicht bakteriellen Ursprungs), Phlebektasien, Hydrops pedum, Varices crur., nicht entzündlich „aufgetriebenem Leib“ u. Ae.

V. Als spätere Stadien des Descensus sind nach den Blutuntersuchungen aufzufassen folgende Combinationen:

a) Retroversio-flexio mit ausgeprägtem Descensus oder mit starker Cystocele,

b) Anteversio-flexio schon beim beginnenden Descensus neben Cystocele (wenn also die Scheide sich bei bereits zu sinken begonnenem an tevertirtem Uterus zu invertiren beginnt, sind die Gefässe schon längere Zeit und weiter erschlafft, als bei retroflectirtem Uterus mit Cystocele ud be'ginnendem Descensus);

c) Descensus uteri retroflexi cum descensu ovariorum;

d) stärkerer Descensus uteri retroflexi mit geringer Cystocele (also Frühstadium), aber mit auffallenden schlaffen Wandungen;

e) Prolapsus uteri incompletns sive completus, aber in Abhängigkeit von Begleitmomenten (Entzündungen, Exulcerationen, Staunngen etc.).

Vl. Aus dem Auftreten der activen hochpotenzirten Congestion bei Retroversio-flexio uteri obne Subinvolution (schon in Frühstadien) geht auch aus diesen Untersucbungen hervor, dass es sich bei dieser Haltung und Lagerung der Gebärmutter um abnorme Verhältnisse handelt, die demnach in vasomotorischen Störungen begründet und jedenfalls mit jenen auf das Engste verknüpft sind. - Weiterer Beweis ist, dass bei Combinationen, z. B. Descensus oder Subinvolutio + Retroflexio uteri, die letztere durch ihre active Hyperämie die mit ersterem vergesellschaftete passive Hyperämie bis zn einem gewissen Grade compensirt. Analoges gilt von der Inversio vaginae als solcher; 'so pfropft sich auch umgekehrt die active Congestion der Retroflexio auf die gleiche der Inversio uteri im Blutuntersuchungsbefunde auf, accumulirt sich zu ihr!

Also auch hieraus dürfte zu schliessen sein, dass Retroflexio und Inversio + Descensus das Gleiche ursächliche vasomotorische lloment haben und dass ferner neben den secundären Circulationsstörungen bei Prolaps die primären nachweisbar bleiben!

VII. Die neben Descensus uteri vorkommende nicht entzündliche 
rasomotorische "Aultreibung des Abdomen" benuht nicht so sehr and meist nicht primär (nicht selten mit allorhythmischer Tachy- seltener Bradycardie gepart) auf venöser, sondern auf arterieller Frschlaffungs-Hyperämie (46). Aniloge Erschlaffungshyperämien finden bei nicht entzündlicher Metritis chronica im Anschluss an Subinrolutio ateri und bei Perversitäten statt: arterielle und venöse Hyperämie können. sich hier wechselseitig paralysiren hinsichtlich des Resultates der Mischblutuntersuchung. Die Verdickung des Organes und die Senkung desselben sind Folgen der Transsudation und der durch dieselbe hervorgerufenen Aenderungen im elastischen Gewebe und im Gewebsinnendruck. Ueber den Beginn der Enteroptose keine hämatologischen Beobachtungen; wahrscheinlich auch in diesem Sinne ätiologischer Connex zwischen Enteroptose und Retroflexio-Descensus $(45,46)$.

VIII. Bei den bakteriellen intrapelvinen, zumal intraperj. tonealen Entzündungen finden wir je nach dem Stadium Congestion oder Stase vorherrschend; da die Entzündungen so schroff primär gegenüber dem Descensus bestehen, und der letztere znweilen, zumal bei tuberculösen Leiden, auf eine Fxacerbation hin sehr rasch zu Stande kommt, ist zu untersuchen, ob nicht die Hyperämie nach Obigem auch die Ursache der Ligamenterschlaffung und des Descensus ist, wie es nach den Mischblutuntersuchungen wahrscheinlich ist. ( $\mathrm{Z}$ weifel-Abel (43) hatten z. B. unter ihren einseitigen Ovariotomirten 63 pCt. Retroflexionen bei Pelveoperitonitis, aber nur $43 \mathrm{pCt}$. ohne dieselbe, und zwar mobile Retroflexionen.)

IX. Wird ein retroflektirt descendirter Uterus gravid, so tritt hochpotenzirte Congestion, zuweilen sogar nur solche, ein; Stase kommt nur in Folge von Incarceration oder Abort vor; wird reponirt, so tritt einfache Congestion + Hochpotenz an Stelle der Stase. In der zweiten Hälfte der Schwangerschaft besteht letztere Combination stets. Bei gleichzeitigem Descensus uteri überwiegt die Stase; der Literus ist weit schlaffer; hierin die Ursache, dass die descendirt retroflektirten schwangeren Utereri so sehr viel seltener sich spontan anfrichten (Pradisposition zur Incarceration, 44). Auch bei einwandig retinirten Eiresten oder retinirten Aborteiern kommt es leicht zur secundären Retroflexio uteri oder zur Retroflexion, wenn Verticalstellung oder einfache Retroversion (46) Forher bestanden laben - alles dieses unter ödematöser Frschlaffung. Ferner sind nach Küstner (47) die Früchte aus spät corrigirten retroflektirten Fruchthalteru mangelhaft ernährt.

X. Retinirende und fixirende Behandlung bringt im Wesentlichen Aenderungen hinsichtlich der secundären Circulationsstörungen zu Wege (passive Hyperämie), also ein weiterer Beweis für das Primäre der activen Congestion.

XI. Bei Descensus hypoplastischer Uteri ist an sich einfache Congestion oder Stase vorberrschend, und zwar, wenn mit Anteflexion combinirt, mter Hinzutritt geringer höher potenzirter Congestion, wäbrend der einfache retroflektirte infantile Uterus diese vermissen lasst bei Complicationen, - sonst aber, wie gewöhnlich, mit hoch potenzirter Blutmischung gepaart ist. Es ist zur Zeit nicht zu unterscheiden, ob bei ersteren Fälen auch wieder der Descensus oder die relative Elongatio colli mit der activen Congestion gepaart geht; wahrscheinlich aber der Descensus, weil bei hinzutretender Cystocele 
Aetiologie und Pathologie der Senkung der weiblichen Genitalien. 221

die höhere Potenz noch häufiger vorkommt. Es liegt nahe, die infantile Tiefe der Excavatio rectouterina als eine relative Bindegewebshyperplasie zu Folge der Hyperämie gegenüber den activen Geweben aufzufassen.

XII. Hypertrophie durch Hyperämie liegt zu Folge den Vischblutuntersuchungen anscheinend den Bindegewebshyperplasien bei descendirten and prolabirten Uteri vor, und zwar bei Dickenzunahme der Corpuswand (nicht infectiöse Myometritis chronica) und des Collum (ausser dem Oedem) theils durch Entzündungs-, theils durch venöse Staungs-Hyperämien, welche neben Subinvolution der puerperalen Gewebe auch noch Bindegewebswucherung hervorrufen, - und bei Elongatio colli durch active Congestion (zu der sich Erschlaffungscongestion bei puerperalen Fällen gesellen kann); denn Stase wurde bei Elongatio colli nur jenseits des Klimax und bei gleichzeitigen Phlebektasien gefunden, hingegen stets hoch potenzirte Erythrocyten. (Congenit. Cervixhypertrophie bei Spina bifida lumb., 15.)

Bei sehr schlaffer Collumwand bewirkt ein Ringpessar (auch ohne Lazeration der Muttermunds-Commissur) auf die Dauer Ektropium arteficiale mit papilloider Wucherung der Cervicalmucosa zu Folge der Erschlaffungshyperämie (22).

\section{Literatur und Vorarbeiten.}

1. Schaeffer, O., Exp. v. d. inn. Genit. auslösbare Fernerschein., besondel's des Blutgefässsystems. Mon. f. G. u. G. 1902. XV. 423. - Centr. f. G. 1901.

2. Landerer, Die Gewebsspannung. Leipzig. 1884.

3. Martin; A., Ref. über Prolapsoperationen in d. Verh. der Deutsch. Ges. für Gyn, 1903. Würzburg.

4. Küstnel, Ref. über Prolapsoperation in d. Verb. der Deutsch. Ges. für Gyn. 1903. Würzburg.

5. Fritsch, Discussion zu Obig.

6. Kamann, Sammelber. Mon. für Gyn. u. Gebh. XVII.

7. Mangiagalli, Mon. für G. u. G. 1901. XVIIL.

8. Seeligmann, Centr. für G. 1903. XIV.

9. Coe, Mon. für G. u. G. 1901. XIV.

10. Fritsch, Centr. für G. 1900. No. 2. - Deutsche Klin. 1902. No. 47.

11. v. Her ff, Hegar's Beitr. 1900. III.

12. Falk, Centr. für G. 1903. XIV.

13. Schrader, Centr. für G. 1903. XIV.

14. Schaeffer, O., Rosistenzbestimm. der Erythrocyten während Schwang., Geburt, Wochenbett (Ref. der Nat.- u. Aesztevers. 1902. Karlsbad. Ref. in d. Mon. für G.) - item während Uteruscontractionen des graviden und des nicht graviden Organes (Mon. f. G. u. Gyn. 1904 und Kasseler Naturf.Vers. 1903 und v. Winkels Handb. d. Geb. I, 2. Hälfte. 
15. Schaeffer, 0., Bildungsanom, an Genitalien weibl. Föt.: Angeborener Uterusprolaps. Dieses Archiv. 37, 2. - Ber. and Stud. der Münchner Frauenklinik.

16. v. Winckel, Sitzungsber. der Münchner morph. Ges. 1889.

17. Freund sen., Hamburger Nat.- u. Aerztevers. 1901.

18. Fosthorn, Veit's Handb. der Gyn.

19. Bidder, Centr. für Chir. 1874. 97.

20. Penzo, Moleschott's Unters. z. Naturlehre. 1893. Bd. XV.

21. Stirling, Journ. of anat. and phys. 1876. X.

22. Sehaeffer, 0., Artefic. Ektrop. durch Pessar bei schlaffer Collumwand. Münchner med. Woch. 1899. 32.

23. Bier, A., Münchner med. Woch. 1897. 32. -- Virchow's Arch. 147.

23 a. Bier, A., Münchner med. Woch. 1899 - Ther. d. Gegenw. 1902.

24. Klemensiewicz, Fundam. Vers. iber 'Transsud. Graz. 1883.

25. Sell heim, Hamburger Nat.= u. Aerztevers. 1901. - Würzburger Gyn. Vers. 1903. Discussion.

26. Frazier u. Holloway, Leakocytose bei Unterleibsarkom. Univ. of Penns. med. bull. 1901. Dec.

27. Pinzani, Zunahme der Erythrocyten und des Hämoglobins nach Kastration. Arch. di ost. a gin. 1898. Nov.

28. Sfameni, Abnahme des $\mathrm{Hb}$ u. der Erythrocytenzahl während d. Menses, nachdem sie vorher zugenommen baben. Rass, di ost. e gin. 1899. Jan. Febr.

29. Thióbaut, Blutunters. bei Uterus-Myomen. Jeukocyten (bes. d. polynucl.) dabei. Ann. de l'Inst. de St. Anne-Brisset. 1898. (Ch. Buleus.)

30. Döderlein, Nicht infect. Metritis (Cervicitis). Veit's Handb. der Gyn. und Gräfe's Sammlang. III.

31. Koblanck, Einige Störungen der phys. Functionen der weiblichen Sex.Org.: Onanie und Menorhag. sowie Amenorrhoe. Zeitschr. für Gyn. und Gebh. 43.

32. Heil, Dieses Archiv. 1895̃. Angeborener Ut.-Prolaps, ebenso folgende:

33. Qvisling, Archiv für Kinderh. 1891.

34. Krause, Centr. für Gyn. 1897.

35. Veit, Zeitschr. für Gyn. und Gebh. 1878.

36. Hanssen, Münchner med. Woch. 1897.

37. Radwansky, ibid. 1898.

38. Martin, A., Ref. d. Würzb. Congr.-Verh. Münchner med. Wooh. 1903. 30. VI.

39. Dützmann, Leukocyten bei Erkrankungen dor weibl. Genitalien, Mon. f. Gebh. 1903. XVIII. 1.

40. Theilhaber u. A. Meier, Mesometritis chronica. Dieses Arch. 66. 1. T'heilhaber, Insufficienz des nicht schwangeren Uterus. Münch. med. Woch. 1902. 41, 1698.

41. Richelot, Sklerosis Uteri und wahre Metritis. Compt. rend. de la soc. de Gyn. de Paris 1900. 4, V. Ferner: Pichevin, Petit, Cholmogoroff, Reinicke. Areh. f. Gyn. 53. S. 340 . 
Aetiologie and Pathologie der Senkung der weiblichen Genitalien. 223

42. Kentmann, Myometritis oedematosa. Mon. f. Geb. u. Gyn. VIII. 4. Schultze-Vellinghausen, Instrumentelle Perforation des Uterus. C. f. G. $1902.27,723$.

43. Abel-Zweifel, Zur Prophylaxe der Retroflexio uteri. Leipzig. Ges. f. Geb. 1898. 17. I. Sitz.-Ber.

44. Menge, Ebendas. Discussionsbemerkung über Retroflexio nteri gravidi.

45. Langerhans-Menge-M. Sänger, Ebendas. Retroflexio uteri und Enteroptosis.

46. O. Schaeffer, Ueber Retroflexion (Mon. f. G. u. G. 1898).

47. Küstner, Retroflexionsdebatte des Leipziger deutschen GynäkologenCongresses.

48. Liek-Eiselsberg, Einfluss der arteriellen Hyperämie auf die Regeneration. Arch. f. klin. Chir. 67, 2. 1902. 